\title{
Modeling poultry and maize sector interactions in southern Africa under a changing climate
}

\author{
Charles Mensah ${ }^{1}$ and Dolapo Enahoro ${ }^{1, *}$
}

January 07, 2022

${ }^{1}$ International Livestock Research Institute (ILRI), c/o the International Water Management Institute, IWMI-Ghana, PMB CT 112, Cantonments, Accra, GHANA.

*Corresponding author email: $\underline{\text { d.enahoro@cgiar.org }}$

This document contributes to foresight-related research supported by the CGIAR Research Program on Policies, Institutions, and Markets (PIM), led by the International Food Policy Research Institute (IFPRI). The authors also acknowledge funding support from the CGIAR research program on Livestock, led by the International Livestock Research Institute (ILRI). This report is a draft version and has not gone through the standard peer review procedures of IFPRI or ILRI. The authors accept full responsibility for all errors and omissions, and welcome feedback on the content of the report.

\section{Summary}

- This study explores how regional-level interactions of livestock and crop sectors influence the capacity of a southern Africa sub-region to meet its future demand for livestock-derived foods.

- It uses a spatial equilibrium modeling framework to simulate regional trade in poultry and maize products in Malawi, Mozambique, South Africa, and Zambia.

- Model outputs on the demand, production, and trade of poultry products and maize are compared for a baseline and an alternative future scenario representing drought conditions.

- The study's abstraction of a regional approach to livestock and feed sector interactions in the selected region highlights the role of markets in addressing cross-boundary challenges related to food demand expansion and resource management.

- Results imply that the study countries could benefit from addressing their growing demands for livestock-derived foods using a harmonized approach. Further, regional livestock markets may offer cushioning effects to the impacts of climate change in at least one of the countries.

- However, improved quality data and an enhanced specification of the analytical model to better account for the nuances of livestock and feed trade in the region and for varied scenarios of future climate change will be needed, to extend the current study to practical policy application.

Keywords: foresight analysis, livestock, feeds, climate change, markets, regional trade 


\section{Introduction}

A rise in animal-source food demand in developing countries has been attributed to increased urbanization, rising income levels and population growth (Popkin, 2004; Fukase and Martin 2020). While this phenomenon, previously described as the livestock revolution (Delgado et al. 2001) may have played out more discernably within some regions (e.g., countries in Asia) than in others (e.g., countries in Africa) (Pica-Ciamarra and Otte, 2011), there are indications that it will become stronger overall (Komarek et al. 2021). Developing countries have been growing much more rapidly than industrial countries, with observed shifts in diets away from starchy staples and towards animal-based products and fruits and vegetables (Fukase and Martin 2020). It is also projected that between now and 2050, per capita demand growth could be a more important driver of food demand than population growth (Fukase and Martin 2020; Komarek et al. 2021).

So far, the growth in demand for animal-sourced foods has gone mostly unmatched by an expansion in domestic production in many of the affected countries (Thornton, 2010; Herrero et al. 2014). However, the increase in demand for livestock-derived food products, i.e., foods sourced from farmed terrestrial animals, has also led to increased local demand for livestock feeds, fuelling concerns about the future management of natural resources (Herrero et al. 2013). Some studies suggest that approaching the diversity of developing regions' livestock systems holds potential to meet a critical demand for livestockderived foods in these countries, in ways that are sustainable, responsible and efficient (ILRI 2019). For example, increases in domestic livestock production to meet higher demand for animal-source foods are expected to contribute to global climate change, but not in the same way or at the same levels of intensity as can be expected from the expansion of production in industrialized countries or production systems (IUCN, 2010). Increased intakes and production of animal-source foods in poorer regions on the other hand are considered to offer tremendous benefits for the food security, nutrition, and livelihoods of the poor (Enahoro et al. 2018; Alonso, Dominguez-Salas, and Grace 2019; Randolph et al. 2007; Baltenweck et al. 2020).

In regions such as southern Africa, more than 80 percent of the livestock population is raised by smallholder farmers (SADC 2006). Although policy action in agriculture has traditionally focused on crop production, the growing demand for livestock products in these regions will seem to support an enhanced focus on development of their livestock sectors (Tui, Rooyen, and Mninde 2006). The production of grains and other feedcrops needed as biomass to support livestock production is however threatened by climate change, and according to Santpoort (2020), may impact on the capacity of developingregions to meet future food needs and address challenges posed by hunger and malnutrition. In particular, higher anticipated temperatures coupled with more frequent and/or intense droughts, are expected to lead to declines in the productivity and production of maize and other important staple food crops in southern Africa (Hoffman, Kemanian, and Forest 2018; FAO 2018). This will impact on the production, availability and trade of animal feeds, mirroring global conditions where biomass shortfalls linked to animal production have contributed to an increased volatility of grain markets, and to higher food prices (Shiferaw et al. 2011; Rosegrant, Tokgoz, and Bhandary 2013).

Feed crops or crops that have uses both as human food and livestock feeds, already play an important role across Africa (Mottet et al. 2017). Maize in particular is a key staple food in the region, its improved supply having aided recently to reduce the region's characteristic undernutrition (Andersson et al. 2017). 
As climate threats increase, however, there is increased risk of shortages in supply of the crop for human food or livestock feed, and increased competition between the two. Studies such as Shiferaw et al. (2011) have highlighted the importance of crop breeding to overcome biotic and abiotic stresses affecting crop production that are related to changing climatic conditions, as well as the roles of improved agronomic practices. In this study, we explore in addition the role that regional trade and markets play in the capacity of developing countries to meet their future demand for livestock-derived foods and livestock feed biomass. The focus of the study is on four countries in southern Africa, i.e., Malawi, Mozambique, South Africa, and Zambia. These four countries were the focus of a complementary study analyzing the use of grasses and rangelands in ruminant production in southern Africa under climate change (Enahoro et al. 2021). The current and previous study were part of a trans-disciplinary research program, 'Southern Africa- Towards Inclusive Economic Development (SA-TIED)', exploring regional challenges related to inequality, climate and energy, and economic growth, amongst others (https://sa-tied.wider.unu.edu/, accessed December 28, 2021).

Emphasis of the current study is on poultry, which has the stongest growing demand for animal-source foods in the selected region, and maize, a major feed crop used in poultry production across southern Africa. Specific objectives of the study are to (1) analyze quantitatively the dynamics of demand and supply of poultry products (meat and eggs) and maize in Malawi, Mozambique, South Africa, and Zambia, (2) assess the competition for maize as human food and livestock feed in the context of individual-country and regional-level markets for agricultural products, and (3) assess how food and feed market outcomes potentially evolve in the region under an abstraction of frictionless trade, and for a scenario of drought conditions imposed by climate change in 2030.

\section{Background}

An earlier report by Delgado and others projected that globalization, increased urbanization, population growth, and higher incomes will lead to a revolutionary increase in the demand for livestock-derived food products in developing economies around the world (Delgado et al. 2001). This growth has been observed in Southern Africa, at least since the early 2000s, and is attributed to many factors including changing tastes and preferences (Taha and Hahn 2015). In South Africa, where per capita demand for livestock products is highest within the region (Statista, 2021), per capita consumption of poultry meat, beef, and pork increased from 38.4 kilograms $(\mathrm{kg}), 17.8 \mathrm{~kg}$, and $4.4 \mathrm{~kg}$, in 2010 to $41.2 \mathrm{~kg}, 21.3 \mathrm{~kg}$ and $5.0 \mathrm{~kg}$, respectively, by 2017. National statistics databases further indicate that the country became a net importer of beef, mutton and goat meat in the 2000s, transitioning from an earlier net exporter position (FAO 2020). While income gains and other driving factors may have been slower in other countries in the region, similar trends are observed in the demand for livestock products (FAO 2020).

The growth in demand for livestock products has not been matched by similar growth in domestic livestock production. Higher unmet demand has thus led to an increased dependence on meat imports. For poultry in South Africa, meat imports come in mostly from Australia, South America, and Oceania countries (DAFF 2017). The high dependence on meat imports holds inspite of South Africa, a large economy in both population size and income terms, having a relatively well developed livestock sector. South Africa however remains the main hub for intra-regional livestock trade among the four countries included in this study. In Malawi, Mozambique and Zambia, low animal productivity and production, and less developed livestock markets and infrastructure could be contributing to the high inflows of livestock 
products from outside the region (Homann-Kee Tui, Van Rooyen, and Minde 2011). Across the selected sub-region, however, an estimated 19 million poor persons or more derive at least part of their livelihoods from livestock production (Robinson et al. 2011). This potentially makes a case for increasing the attention of policy or other interventions to the livelihood and nutrition potential of the sector (ILRI 2019). Issues related to livestock feed use and availability are an important component of that exploration, as nutrition of the animals is known to make up the bulk of livestock production costs. Within semi-arid areas of the region where livestock feed biomass is perhaps scarcest (Enahoro et al. 2021), feed costs account for more than 75 percent of the total production costs (Matope et al. 2019). Biomass production may be threatened by a rapidly changing climate globally (Enahoro et al. 2021), while ineffective markets for livestock contribute to hindering the growth of livestock productivity within southern Africa (Homann-Kee Tui, Van Rooyen, and Minde, 2011).

Southern Africa under climate change is in general growing drier and hotter (Mafongoya et al. 2017). Impacts of such changes are experienced in livestock systems in many ways, including through changes in the availability and quality of biomass for livestock feeds, water supply and quality, the dynamics of livestock diseases, and ecological processes (Thornton et al. 2009). Climate impacts thus come as shocks to animal productivity and total livestock production, and affect the profitability of livestock activities (Thornton et al. 2009). Since majority of southern Africa's livestock farmers are smallholders, the impacts of climate change in the region are significant, affecting not just the production of livestock products to meet demand for animal-source foods, but ithe food security and incomes of millions (Dzama 2016 ; Thornton and Gerber 2010). These lead in turn to declining overall resilience of poor rural households and affect the environment, society and the economy at large (Thornton and Gerber 2010; IUCN 2010).

Against the background of higher demand for livestock-derived food products in the greater Southern Africa region (i.e., the study countries plus Botwana, Zimbabwe, Namibia and about nine others), national governments in the region may have increased their focus on investment and policy support to the more than 80 percent of small-scale farmers who own more than 80 percent of the region's livestock (SADC 2006). A common discussion point has been the need to enhanceregional trade, with the aim to facilitate trade between less-endowed countries and others with better-developed livestock markets and supply chains (ibid.). Assessments are however needed that can quantify the roles of such livestock markets and trade within the critical discussion that links increased demand and production of livestock-derived food products to the competition for feed crops. This study contributes to the discussion with its use of a partial equilibrium, multi-market framework to analyze the potential role of poultry and maize (food and feed) markets in the context of a rapidly growing demand for poultry products in Malawi, Mozambique, South Africa, and Zambia.

\section{Methodology}

A multi-market model framework was used to assess food and feed market interactions in a selected subregion in southern Africa covering Malawi, Mozambique, South Africa, and Zambia. This framework specifies differentiated (traditional meat, commercial meat, and egg) poultry markets alongside markets for maize as human food or livestock feeds. It follows the initial specifications of an integrated epidemiological-economic model previously applied to analyzing the effects of animal disease in southern America (Rich and Winter-Nelson 2007); and of amore recent adaptation, the Vietnam Pig Model (VPM) used to analyze pig and maize sector interactions in Vietnam and Uganda (Lapar et al. 2018). This model 
is currently being pilot tested in country-specific (e.g., Tanzania and Kenya) applications that include multiple livestock types, such as bovine, small ruminant animals, pigs, and chickens, and track multifaceted development outcomes, such as household food security, livelihoods, and gender equity impacts (Bahta, et al. 2020). In the current application, we apply the model to analyzing annual demand and supply of poultry and maize in the study region from a base year of 2015, to a future year 2030.

The main equations of the model, defined using the first order (Kuhn-Tucker) conditions of a quadratic, partial equilibrium, problem are specified in Table 1.

Table 1: Equations of the Regional Livestock and Feed model

\begin{tabular}{|c|c|c|}
\hline \# & Equation Name & Mathematical Specification \\
\hline 1 & Crop area & $\ln A R_{f, r, u}=a \alpha_{f, r, u}+\sum_{f,}\left(a \beta_{f, f f, r, u} * \ln P S_{f f, r, u}\right)+\sum\left(a \gamma_{f, l . r, u} * \ln P S_{l, r, u}\right)$ \\
\hline 2 & Crop yield & $\ln Y L D_{f, r, u}=y \alpha_{f, r, u}+\sum_{f f}\left(y \beta_{f, f f, r, u} * \ln P S_{f f, r, u}\right)+\sum_{l}\left(y \gamma_{f, l . r, u} * \ln P S_{l, r, u}\right)$ \\
\hline 3 & Crop supply & $S C R_{f, r, u}=A R_{f, r, u} * Y L D_{f, r, u} * M P A R_{f, r c o n v}$ \\
\hline 4 & Livestock supply & $\ln S L V_{l, r, u,}=l \alpha_{l, r, u}+\sum_{l l}\left(l \beta_{l, l l, r, u} * \ln P S_{l l, r, u}\right)+\sum_{f}\left(l \gamma_{l, f, r, u} * \ln P S_{f, r, u}\right)$ \\
\hline 5 & Food demand & $\begin{aligned} \ln D F D_{c, r, u}= & d \alpha_{c, r, u}+\sum_{c c}\left(d \beta_{c, c c, r, u} * \ln P D_{c c, r, u}\right)+\left(d \gamma_{c, r, u} * \ln Y P C_{r, u}\right) \\
& +\left(\operatorname{lnPop}_{r, u} * 1000\right)+\left(d \delta_{c, r, u} * \ln \left(1-S H K_{c, r, u}\right)\right)\end{aligned}$ \\
\hline 6 & Feed demand & $\begin{aligned} \operatorname{lnDFeed}_{f, r, u}= & f \alpha_{f, r, u}+\left(\operatorname{lnPop}_{r, u} * 1000\right)+\ln \sum_{l} S L V_{l, r, u} \\
& +\sum_{f f}\left(f \beta_{f, f f, r, u} * \ln P D_{f f, r, u}\right)+\sum_{l}\left(f \gamma_{f, l, r, u} * \ln P S_{l, r, u}\right)\end{aligned}$ \\
\hline 7 & Commodity inflow & $\sum_{r r}\left(T Q_{c, r r, r, u}\right)+M_{c, r, u} \geq D F D_{c, r, u}+\sum_{f}\left(I D E N 1_{c, f} * \operatorname{DFeed}_{f, r, u}\right)$ \\
\hline 8 & $\begin{array}{l}\text { Commodity } \\
\text { outflow }\end{array}$ & $\sum_{l}\left(I D E N 2_{c, l} * S L V_{l, r, u}\right)+\sum_{f}\left(I D E N 1_{c, f} * S C R_{f, r, u}\right) \geq \sum_{r r}\left(T Q_{c, r, r r}\right)+X_{c, r, u}$ \\
\hline 9 & Domestic trade & $P S_{c, r, u} / M P A R_{c, r c o n v \prime}+M A R G D_{c, r, r r, u} \geq P D_{c, r r, u}$ \\
\hline 10 & Imports & $\left(P W_{c}+M A R G W_{c}\right) * N E R *\left(1+T A X_{c, M^{\prime}}\right)+I M T_{c}+M A R G M_{c, r, u} \geq P D_{c, r . u}$ \\
\hline 11 & Exports & $P S_{c, r, u} / M P A R_{c, r c o n v}+M A R G X_{c, r, u}+I X T_{c} \geq P W_{c} * N E R *\left(1-T A X_{c, x x^{\prime}}\right)$ \\
\hline 12 & Import Quota & QUOT $_{c, M^{\prime}} \geq \sum M_{c, r, u}$ \\
\hline 13 & Export Quota & $Q U O T A_{c, X^{\prime}} \geq \sum_{r, u} X_{c, r, u}$ \\
\hline
\end{tabular}

Source: Adapted from Rich \& Winter-Nelson (2007) and Lapar et al., (2018).

The equations in Table 1 specify the optimum crop area (equation 1), yield (equation 2) and supply (equation 3 ) of the crop commodity $F$ associated with human food and livestock feed use in each region 
$R$ in the model. Human food consists of commodities $(C)$ which could be crop $(F)$ or livestock $(L)$ commodities, while feeds are crop $(F)$ commodities only. In addition, production or supply indicators in the model are distinguished by $U$, a designation for rural or urban location. Livestock supply is defined using equation 4, while food (poultry meat, eggs, maize) and feed (maize) demand are specified by equation 5 and equation 6 , respectively. Trade between the regions in the bloc is solved using inflow and outflow specifications (equations 7 to 9), while international trade, i.e., trade between the seven-region bloc and the rest of the world, is specified using equations 10 to 13. In this application of the model, only regional trade has been implemented, in anabstraction of a joint regional strategy. Relevant parameters of the model are defined in Table 2.

Table 2: Key Variables and Parameters of the Regional Livestock and Feed model

\begin{tabular}{|c|c|}
\hline $\begin{array}{l}\text { Variables (VAR) and } \\
\text { parameters (par) }\end{array}$ & Definition \\
\hline$A R$ & Crop area \\
\hline$Y L D$ & Yields of (feed) crops \\
\hline$S C R$ & Supply of (feed) crops \\
\hline$S L V$ & Supply of livestock \\
\hline$D F D$ & Food demand \\
\hline DFeed & Feed demand \\
\hline YPC & Income per capita \\
\hline$P O P$ & Population \\
\hline SHK & Initial (e.g., climate-induced) demand shock \\
\hline$T Q$ & Transport of goods (tons weight) \\
\hline$M$ & Imports \\
\hline$x$ & Exports \\
\hline IDEN1 & Identity matrix used for feed demand in inflow equation \\
\hline IDEN2 & Identity matrix used for livestock supply in outflow equation \\
\hline IMT & Implicit import tax \\
\hline IXT & Implicit export tax \\
\hline$T A X$ & Import-export tax \\
\hline NER & Nominal exchange rate \\
\hline MPAR & $\begin{array}{l}\text { Market parameters related to (CONV), (PMARGPR), (CTA), (XPROC) and } \\
\text { (FEEDCONV) }\end{array}$ \\
\hline MARGD & Marketing margin for internal trade \\
\hline MARGW & Marketing margin between world FOB and CIF prices \\
\hline MARGM & Marketing margin for imports \\
\hline MARGX & Marketing margin for exports \\
\hline QUOTA & Import/Export quota limits \\
\hline$P S$ & Producer price \\
\hline$P D$ & Consumer price \\
\hline$P W$ & World Prices \\
\hline$\# \alpha, \# 6, \# \gamma$ & $\begin{array}{l}\text { The exogenous (alpha, beta, and gamma) parameters of the empirical } \\
\text { relationship defining the \# equation (where \# is area, yield, etc.) }\end{array}$ \\
\hline
\end{tabular}

Source: Adapted from Rich \& Winter-Nelson (2007) and Lapar et al., (2018). 
The regional livestock and feed (sectors) model has been specified so as to represent seven entities or regions interacting through trade in two inter-connected agricultural sub-sectors, i.e., poultry and maize. In an adaptation closely charting Rich and Winter-Nelson (2007), three of the specified regions represent one each of three countries in the region (i.e., Malawi, Zambia and Mozambique), while the largest of the countries in the bloc, i.e., South Africa has been broken into four separate regions. Table 3 presents the names, corresponding countries, and major descriptions of the study regions included in the current study. Within the poultry sub-sector, three production systems have been specified, namely traditional chicken (meat), commercial broiler (meat), and commercial layer (egg) systems. For analytical convenience, each of these systems was assumed to produce one livestock product type only, i.e., traditional mixed chicken system produced meat (ignoring the co-production of eggs), commercial broiler system produced meat, and commercial layer system produced eggs (ignoring the meat obtained from sale/slaughter of spent layers). As such, there are three distinct markets to consider in the model: the traditional (local meat) chicken meat, commercial broiler (broiler meat), and commercial layer (egg) product markets.

Table 3: Regions specified in the Regional Livestock and Feeds Model

\begin{tabular}{lll}
\hline Region code & Country Association & Designation \\
\hline MWI & Malawi & National \\
MOZ & Mozambique & National \\
ZMB & Zambia & National \\
NWP & South Africa & Northwest Province \\
MLP & South Africa & Mpumalanga Province \\
FSP & South Africa & Free State Province \\
ROP & South Africa & Rest of South Africa, i.e., excluding North West, \\
& & Mpumalanga and Free State Provinces \\
WORLD & World & World, excluding Malawi, Mozambique, South Africa, \\
& & Zambia \\
\hline
\end{tabular}

Source: Authors, as specified for this study.

According to our model specification, the seven regions of the four southern Africa countries operate as a harmonized economic entity, in that they enjoy frictionless trade, being able to exchange commodities with one another freely. The only barrier simulated in the model was the physical distances between the regions and to external boundaries such as sea ports. While this provides for analytical convenience, as for example the model and results could represent closely the effects of a harmonized approach to livestock policy that includes regional livestock market development, it imposes rather strong assumptions on the analysis, such as the use of a single exchange rate for the defined trading bloc and the rest of the world. 


\section{Input Data}

The input data for the model simulations have been derived from multiple sources spanning published national statistics, sub-national livestock statistics, nationally representative country surveys, and published and grey literature. Table 4 presents the data sources by country.

Table 4: Sources of Model Input data by Country

\begin{tabular}{|c|c|c|}
\hline Country & Data & Source (s)/references \\
\hline \multirow[t]{9}{*}{ South Africa } & Chicken meat production & $\begin{array}{l}\text { Statistics South Africa: Community Survey, } \\
2016 \text { report; Census of Commercial } \\
\text { Agriculture, } 2017 \text { report }\end{array}$ \\
\hline & Provincial population & $\begin{array}{l}\text { Statistics South Africa: General Household } \\
\text { Survey } 2015 \text { report }\end{array}$ \\
\hline & Maize yields & $\begin{array}{l}\text { South Africa Maize Crop Quality report, } \\
\text { 2017/18 }\end{array}$ \\
\hline & Broiler meat consumption per capita & DAFF, 2017 \\
\hline & $\begin{array}{l}\text { Distribution of chicken products' } \\
\text { demand/supply }\end{array}$ & SAPA, 2017; SAPA 2019 \\
\hline & Incomes per capita & Statssa, 2014; FAO, 2020 \\
\hline & Product prices & $\begin{array}{l}\text { United States Department of Agriculture } \\
\text { (USDA); Grain South Africa; NAMC, 2017; } \\
\text { GAIN, 2017; Department of Statistics of } \\
\text { South Africa }\end{array}$ \\
\hline & Export and import volumes & Statssa, 2014; FAO, 2020; GAIN, 2017 \\
\hline & Export/Import tax rates & South African Customs Union \\
\hline \multirow[t]{3}{*}{ Malawi } & Chicken meat production & NSO, 2016; \\
\hline & Product prices, imports and exports & $\begin{array}{l}\text { FAO-GIEWS, 2021; NSO, 2019b; USDA; FAO, } \\
2020\end{array}$ \\
\hline & Population, population growth rates & NSO, 2019a; NSO, 2020 \\
\hline \multirow[t]{5}{*}{ Mozambique } & $\begin{array}{l}\text { Chicken production, maize } \\
\text { production, harvest areas, yields per } \\
\text { hectare }\end{array}$ & $\begin{array}{l}\text { Ministry of Agriculture \& Food Security; } \\
\text { FAO/WFP, } 2019\end{array}$ \\
\hline & Product prices & FAO, 2015; FAO-GIEWS, 2020 \\
\hline & Urban-rural populations & Instituto Nacional de Estatística, 2017 \\
\hline & $\begin{array}{l}\text { Per capita incomes, income growth, } \\
\text { population projections }\end{array}$ & Instituto Nacional de Estatística, 2017 \\
\hline & Maize consumption & $\begin{array}{l}\text { FAO, 2020; FEWSNET, 2018; USDA; Latino, } \\
\text { Pica-Ciamarra, and Wisser, } 2020\end{array}$ \\
\hline \multirow[t]{4}{*}{ Zambia } & $\begin{array}{l}\text { Maize production, yields, areas, } \\
\text { Chicken production }\end{array}$ & CSO, 2015 \\
\hline & Urban \& rural populations, incomes, & Zambia Statistics Agency \\
\hline & Consumption & FAO, 2020, Zambia Statistics Agency \\
\hline & Prices, imports, exports & CSO, 2015 \\
\hline
\end{tabular}

Source: Authors, as derived for this study. 
In addition to the national statistics used to parameterize the model, output data from the IMPACT model (Robinson, Mason d'Croz, Islam, Sulser, et al. 2015) were used to inform the (baseline and scenario) world prices of poultry meat, eggs, and maize, income and price elasticities of demand, and exogenous growth rates of crop and livestock supply under baseline and climate change scenarios to 2030. Relevant IMPACT data are included in the appendix.

\section{Model Simulation}

The model described above was solved recursively over a 15-year horizon, first for a baseline or businessas-usual scenario, and then for an alternative scenario simulating drought conditions in the southern Africa region. Its application to the southern Africa region followed a previous analysis of a southern America region (Rich and Winter-Nelson 2007) and multi-market analyses of the pig and maize sectors of Vietnam and Uganda (Lapar et al. 2018). The link of the adapted regional poultry and maize market model to standard climate modeling was effected using the International Model for Policy Analysis of Agricultural Commodities (IMPACT). IMPACT is a partial equilibrium model that has been used to quantify, simultaneously, the longterm international trade of 159 countries in 62 (total) crop, livestock, and processed commodities, under alternative scenarios of global economic and climate change to 2050 (Robinson, Mason d'Croz, Islam, Sulser, et al. 2015). Model outputs from the IMPACT model informed the exogenous (climate-related) supply shocks to crop areas, crop yields, and livestock supply in the regional livestock model, under the baseline (moderate economic growth or business-as-usual) and alternative scenario of drought conditions imposed by climate change. Data used from IMPACT to parameterize the regional livestock and feed model, which includes climate shocks on crop yields and projected trends in commodity world prices and food and feed elasticities, are presented in the appendix.

The results from the alternative scenarios of the regional livestock model are presented and discussed next, following a presentation of contextual (historical) data on poultry and maize demand, production, and trade in the study region.

\section{Results and Discussion}

\section{Poultry and maize sector dynamics}

While the demand for livestock-derived food products has grown in recent years, i.e., in line with global trends (Fukase and Martin 2020), and the dynamics have been varied across the southern Africa region, growth in poultry demand seems to be a consistent theme. In South Africa, per capita consumption of poultry meat is recorded to have increased 12 percent in the last decade, from $33.4 \mathrm{~kg}$ in 2010 to $37.2 \mathrm{~kg}$ in 2019 (FAO 2020). By the end of the decade, poultry meat consumption was about twice or more times the amount consumed of any other livestock-derived meat type. Per capita consumption of beef and mutton were reported at $17.58 \mathrm{~kg}$ and $3.17 \mathrm{~kg}$, respectively, in 2019 , while that of pork was $4.75 \mathrm{~kg}$ per person, according to the same database. For a summary of starting dynamics of the poultry and maize sectors in the study countries, Table 5 presents per capita consumption, total demand and production of poultry meat and maize in 2010 and 2020.

Per capita consumption of poultry meat increased in all four of the study countries over the last decade, with the fastest growth occurring in Malawi and the slowest in South Africa. The very fast demand growth in Malawi, of more than 3 percent per year, is consistent with demand growth for livestock-derived food 
products in countries that are starting from a very low level of consumption (see Enahoro et al. 2018b). Indeed, on a per capita bases, poultry meat consumption in Malawi was in 2010 less than one-twentieth of consumption of the same in South Africa. Per capita consumption of maize increased in only one country, Zambia, over 2010 to 2020. Meanwhile, maize consumption per person remained unchanged in South Africa but declined in Malawi and Mozambique, by 10 percent or more. Although our analysis includes only a partial analysis of aggregate diets (in that only one livestock type, poultry, and one crop, maize, are included), the observation that poultry meat is increasing while maize consumption is decreasing is consistent with the narrative of an ongoing shift in diets in developing countries to include more animal-source foods while reducing the intake of coarse grains (Popkin 2004).

Table 5: Consumption per capita, demand and production of Poultry Meat and Maize in the Study Countries, 2010 and 2020

\begin{tabular}{lcccccc}
\hline Country & $\begin{array}{c}\text { Per capita } \\
\text { demand, } \\
\mathbf{2 0 1 0}\end{array}$ & $\begin{array}{c}\text { Change to } \\
\text { (kg/per/y) }\end{array}$ & $\begin{array}{c}\text { Total } \\
\text { demand, } \\
\mathbf{2 0 1 0}\end{array}$ & $\begin{array}{c}\text { Change to } \\
\mathbf{2 0 2 0} \\
\text { (1000 MTs) }\end{array}$ & $\begin{array}{c}\text { Total } \\
\text { production } \\
\mathbf{2 0 1 0} \\
\text { (1000 MTs) }\end{array}$ & $\begin{array}{c}\text { Change to } \\
\mathbf{2 0 2 0}\end{array}$ \\
\hline Malawi & 1.64 & $345 \%$ & 23.84 & $470 \%$ & 24.83 & $447 \%$ \\
Mozambique & 2.20 & $79 \%$ & 49.48 & $132 \%$ & 39.74 & $172 \%$ \\
South Africa & 33.38 & $12 \%$ & $1,676.50$ & $28 \%$ & $1,471.57$ & $23 \%$ \\
Zambia & 3.17 & $15 \%$ & 43.05 & $51 \%$ & 42.50 & $19 \%$ \\
& & \multicolumn{7}{c}{ POULTRY MEAT } \\
Malawi & 152.70 & $-14 \%$ & $3,287.00$ & $-4 \%$ & $3,419.41$ & $-11 \%$ \\
Mozambique & 77.72 & $-10 \%$ & $2,173.00$ & $13 \%$ & $2,089.89$ & $0 \%$ \\
South Africa & 95.51 & $0 \%$ & $9,851.00$ & $21 \%$ & $12,815.00$ & $-12 \%$ \\
Zambia & 112.19 & $15 \%$ & $2,049.00$ & $38 \%$ & $2,795.48$ & $-28 \%$ \\
\hline
\end{tabular}

Source: Authors, using FAOSTAT and other national datasets. Where 2020 data was unavailable, the most recent year's data has been used. Total demand includes food and non-food uses.

Growth in the demand for poultry meat is expected to lead to growth in feed maize. This holds as the demand and production of poultry is more strongly linked (than beef and lamb, for example), to use of feed crops that are also edible as human food (Mottet et al. 2017). As total demand for poultry meat increased between 2010 and 2020 in the study countries, so did the demand for maize - but this did not hold in Malawi. In Malawi, total maize demand instead decreased by four percent. Malawi is a very high maize-consuming country and the results, even at the aggregate level, agree with the narrative of a shift in the composition of human diets in the country as incomes and other drivers of food demand are changing. In the countries where demand growth for poultry surpassed that of maize, i.e., in all but Zambia, the rate of change in total demand for poultry meat was generally several (between 2 and 47) times higher than the rate of increase in the demand for maize. This result indicates that poultry meat demand in the study countries does not necessarily have a linear relationship to maize demand. In theory, increases in poultry meat demand could be occurring alongside producers using less feeds (e.g., following increased feed use efficiencies), through the substitution of maize with other poultry feed types, or through increased importsof poultry meat from outside the countries of consumption. Various 
combinations of the identified options could also be in effect. An assessment of the production data suggests that imports have indeed been important for meeting demand for poultry in the study countries. While total demand and production quantities of poultry meat were closely matched in 2010 - for all countries except South Africa, poultry meat demand has grow much faster than production in the years since. Over the ten years of historical data, growth in poultry meat demand surpassed growth in poultry meat production, by 24 percent in Malawi, 5 percent in South Africa, and 32 percent in Zambia. In a notable exception, growth in poultry meat production in Mozambique was higher (at 172 percent) than the recorded growth in poultry meat demand (132 percent) between 2010 and 2020.

While there have been substantial year-to-year fluctuations, the region has generally seen growth in maize feed demand over the last 10 to 20 years, the demand observably growing in Malawi, Zambia and South Africa. In Mozambique, demand seems to have reverted to the levels recorded in the early 2000s after noted increases around 2011. Maize demand as food has similarly grown in the study countries in the same 2000 to 2020 period. Among the countries where maize feed demand has been growing, South Africa dominates (Fig. 1, panel a).

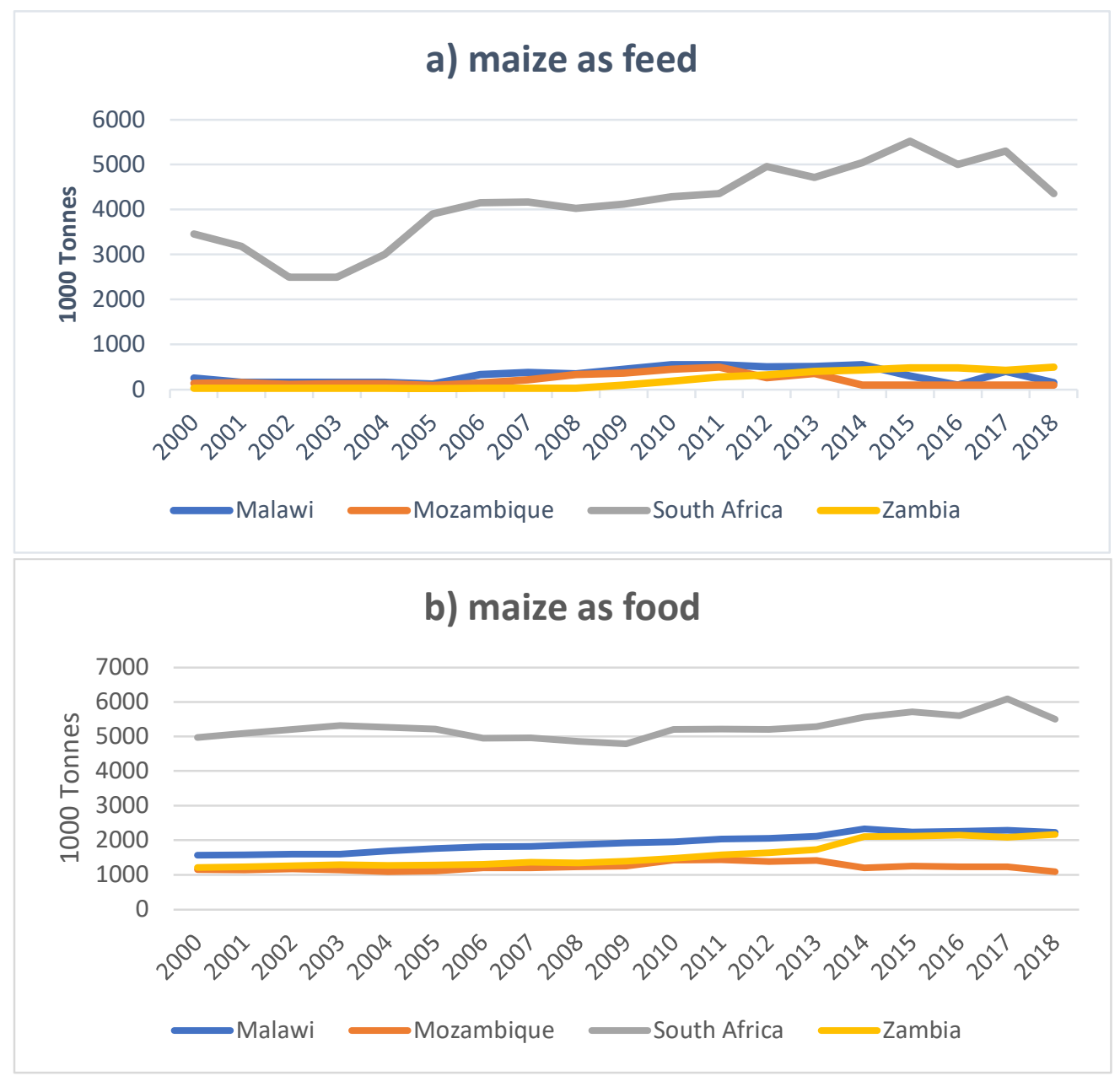

Fig 1: Demand for maize as (a) livestock feed and (b) human food in the study countries, 2000 to 2018 Source: FAO, 2020 
This is due both to the size of the country (and it's high poultry demand), and to a well-developed poultry sector. Between the four study countries, however, the competition for maize as human food may be most relevant for Malawi, where maize consumption as a staple food is also quite high (Fig. 1, panel b). Maize production has also grown over the last decade, as seen in Fig. 2. Over the last decade, the highest annual maize production recorded for Malawi (3.7 million MTs) or for Mozambique (2.18 million MTs) was in 2011, while annual production seemed to have peaked for South Africa (16.8 million MTs) and Zambia (3.6 million MTs) in 2017. Total maize production was across the region increased from 16.15 million MTs in 2010 to 18.85 million MTs in 2018, the most recent year for which complete data is available.

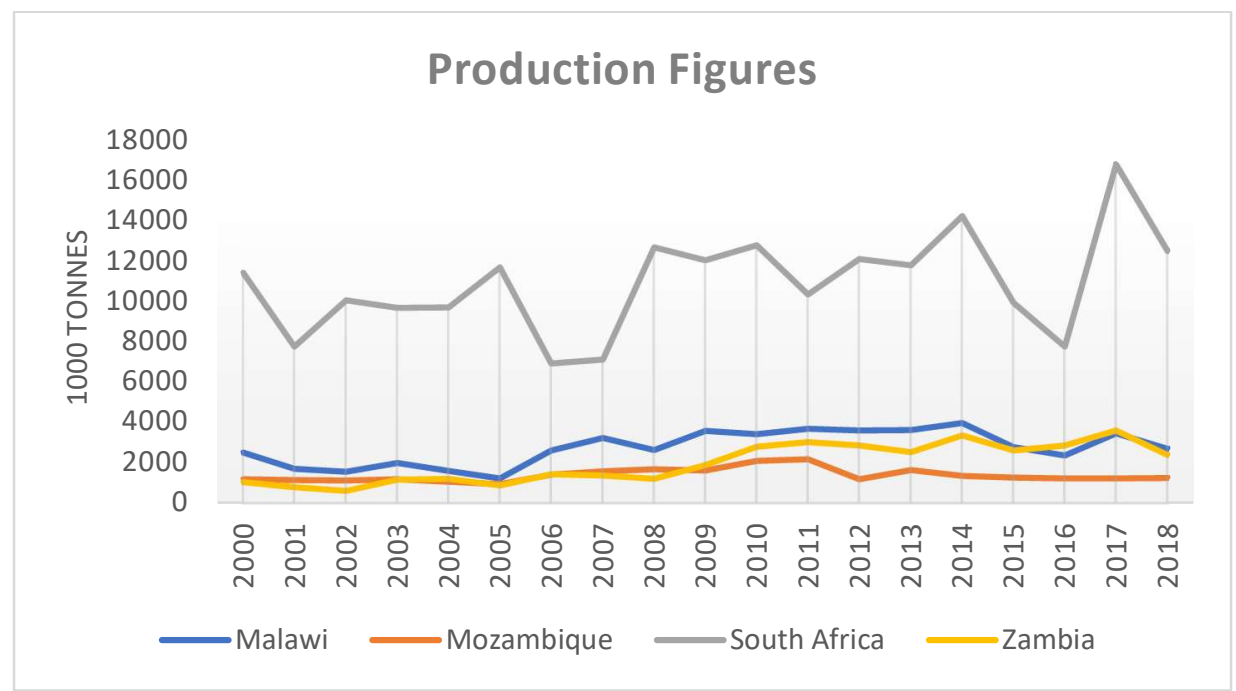

Fig 2: Production of maize in the study countries, 2000 to 2018

Source: FAO, 2020

The current dynamics of the poultry and maize sectors provide relevant context for the model simulations in the base year (2015) and to 2030.

\section{Simulation outputs of the poultry-maize market model}

The model outputs for the base year followed the historical data. South Africa alone accounted for up to 85 percent of the total demand for chicken meat from traditional systems (local chicken). This derives from having the highest income and population (55.39 million in 2015), of the study countries. Zambia, having the lowest population (15.88 million), registered the lowest total demand for local chicken meat (25,700 MT), representing 3.1 percent of the sub-regional total in 2015 (Fig. 3, panel a). Mozambique, with the second largest population (27.04 million) of the four countries, and Malawi (population 16.75 million) accounted for 8.5 percent and 3.4 percent, respectively, of the sub-regional demand for local chicken meat. In the case of broiler meat (from commercial systems), South Africa's 91 percent dominated consumer demand, with Mozambique, Zambia and Malawi accounting for the remainder at 4.4 percent, 1.6 percent, and 2.6 percent, respectively (Fig. 3, panel b). 


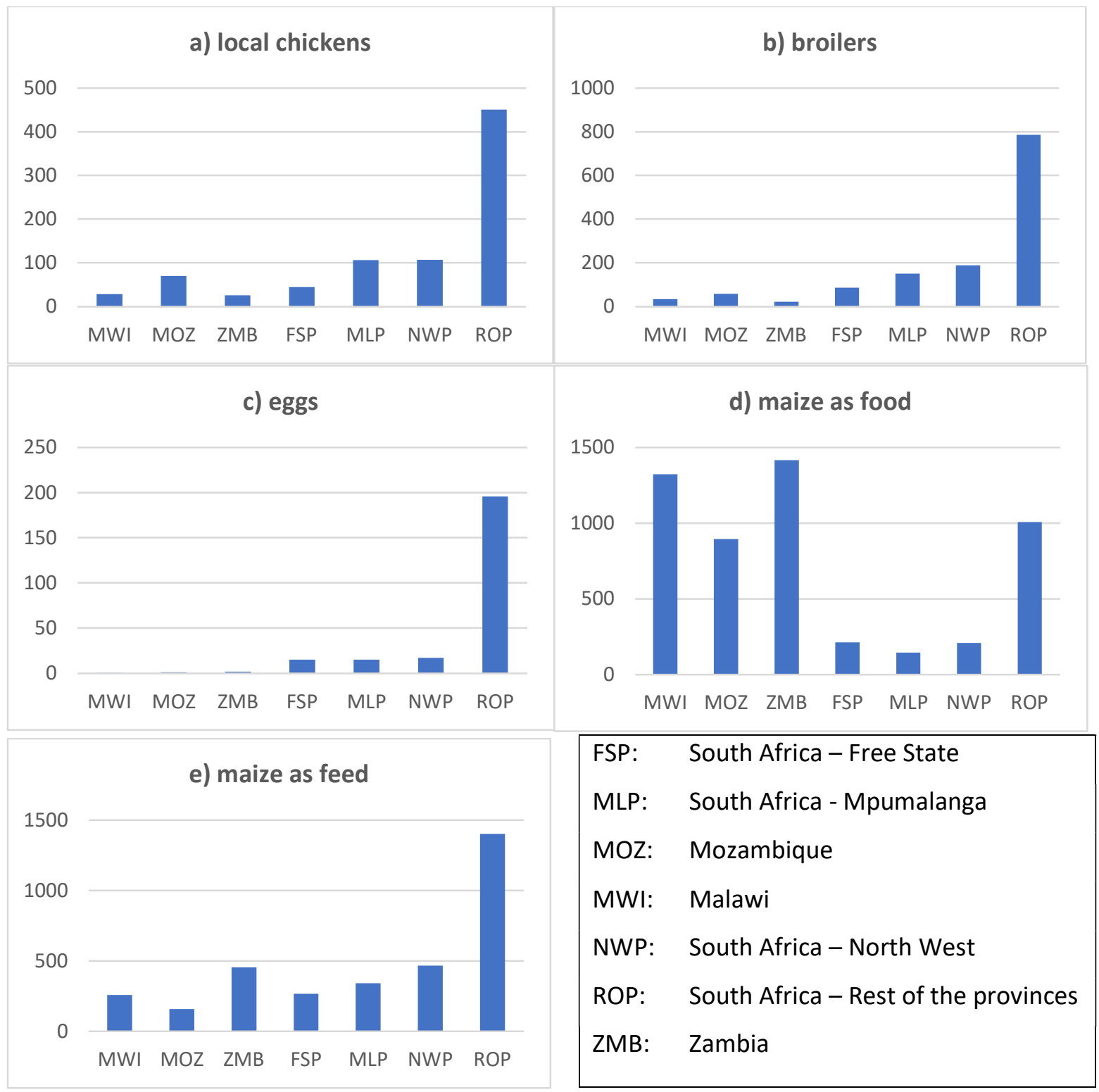

Figure 3: Demand for a) local chickens b) eggs c) broiler meat d) maize as food and e) maize as livestock feed, in the study region in 2015 (1,000 MTs).

Source: Authors, from this study.

The demand for eggs was relatively lower (compared to meat demand) in Malawi, Mozambique, and Zambia, with the three countries accounting together for only two percent of the four-country total (Fig. 3, panel c). South Africa's demand in this case was 98 percent in 2015. The total demand for maize as food is higher in Malawi and Zambia than in Mozambique (which has a higher population) revealing a preference for maize as a staple food in Malawi and Zambia. In Malawi, maize food demand in the base year was 1,323 thousand MT (Fig. 3, panel d). These model outputs are consistent with the historical data and agree with the literature pointing to Malawi and Zambia as major maize-consuming countries. Further, although Mozambique has higher broiler and local chicken meat demand, its maize feed demand 
(157.66 thousand MT) is lower than that of Zambia (453.14 thousand MT). For the disaggregated South Africs regions, North West Province, which produces more than six times the quantity of poultry demand in Zambia, records approximately the same amount of maize feed demand as Zambia, while Malawi, which demands lower quantities of poultry products compared to Mozambique and to Free State Province (in South Africa), has a maize feed demand that is slightly more than Mozambiques's, but slightly less than Free State Province's as summarized in Figure 3, panel e. While feed use rates can be expected to differ across countries even when they utilize similar feed baskets, the simulations for the southern Africa region highlight major differences in the orientation of feed use in the region, i.e., maize has higher relative use as livestock feeds in South Africa and higher use as human food in Malawi. Changes in maize supply, for example due to climate change, could thus have distinctly different impacts on feed interactions in the different countries.

\section{Model projections to 2030}

The total demand for local chicken in the (four-country) region is projected to increase from 0.83 million MT in 2015 to 8.14 million MT in 2030 under the baseline or business-as-usual scenario (Fig. 4). Although all countries are projected to see increased demand for local chicken over the time horizon, the highest growth in demand is projected for South Africa. Mozambique is also projected to experience strong growth in demand between 2015 and 2030. Within South Africa, Free State Province shows the lowest demand growth for local chicken meat. Broiler meat demand in the study countries similarly increases, from 1.33 million MT total for the region in 2015 to 11.72 million MT in 2030 (not included in Fig. 4).

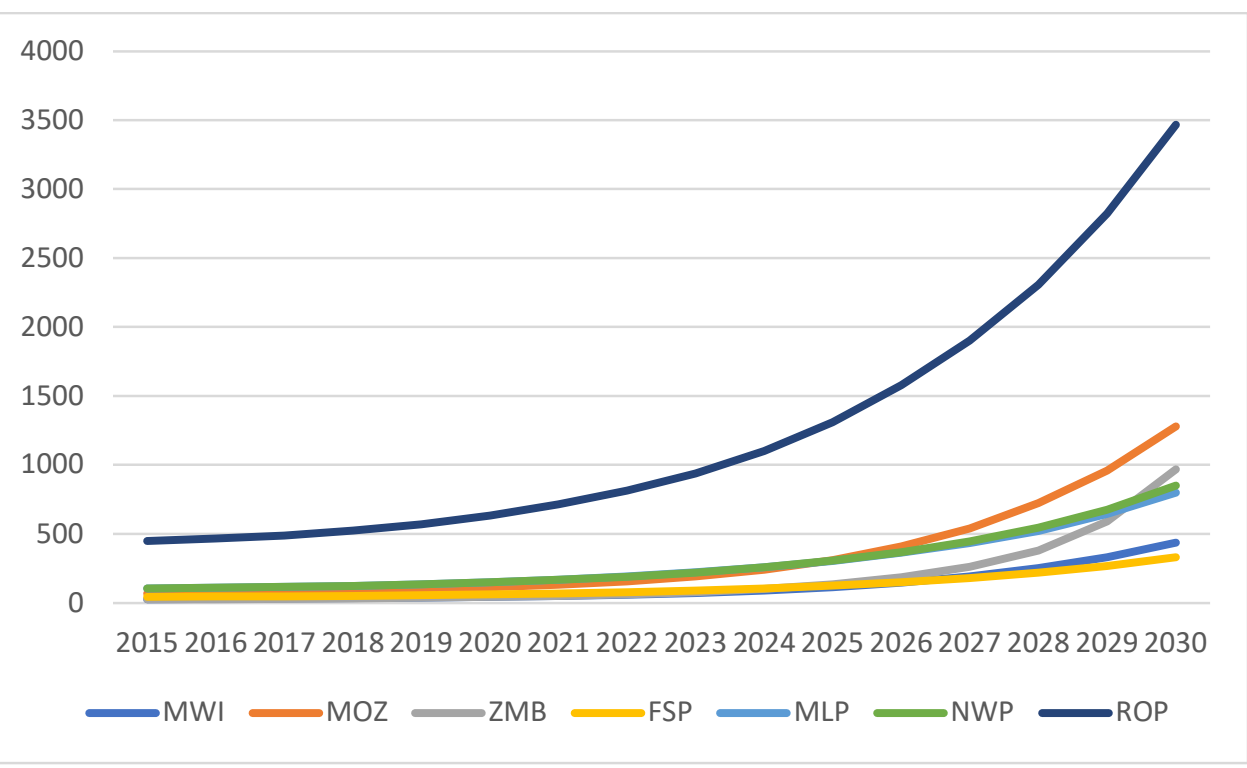

Fig. 4: Demand projections for local chicken meat in the study region under business as usual growth from 2015 to 2030 (1,000 MTs).

Source: Authors, from this study.

While South Africa's estimates drive the regional narrative, its nearly nine-fold increase is actually muted compared to growth rates projected for the other countries in the region. Rapid income and population 
growth drive this results across the region. The growth of egg demand is projected to be much slower than those of local chicken or broiler meat (Fig. 5). Total egg demand increases by 58.3 percent in total for the four countries. On a country-by-country bases, the highest increase is projected for Mozambique (167 percent). South Africa is projected to have the slowest increase in demand over the simulated period, with a cumulative 58 percent increase over the 15 years. Zambia's egg demand growth is projected at 82 percent and Malawi's at 111 percent.

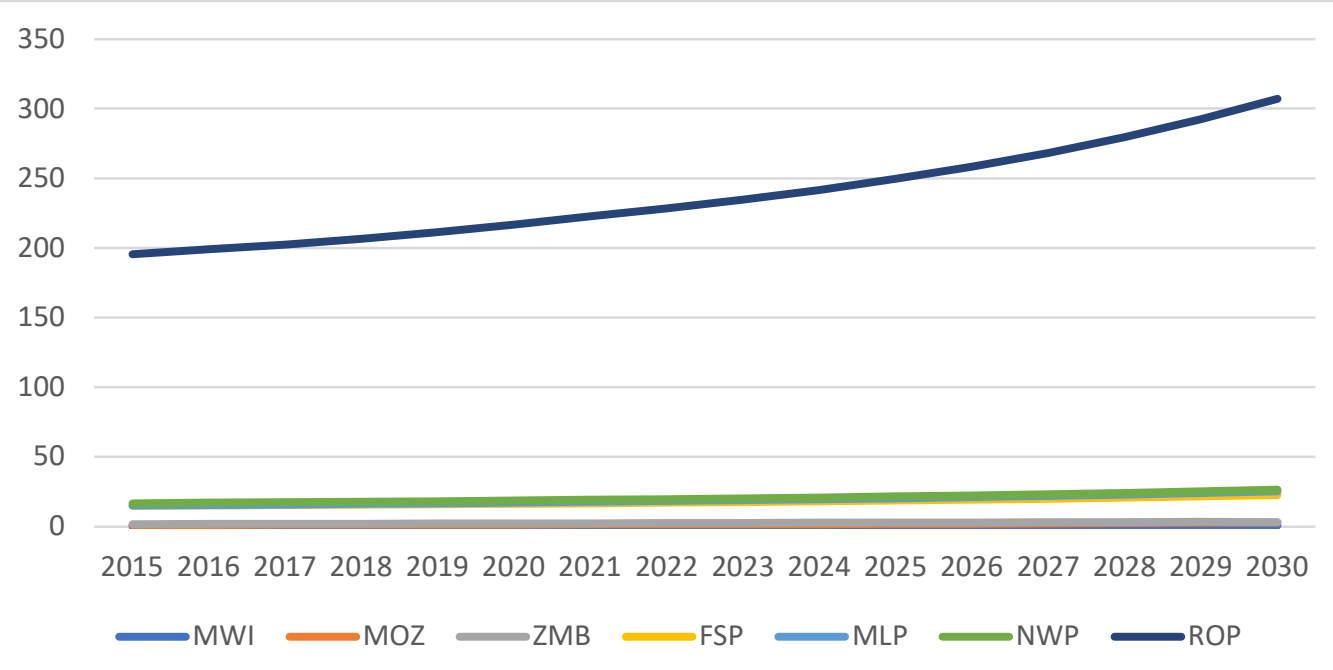

Fig. 5: Demand projections for eggs in the study region under business-as-usual growth from 2015 to 2030 (1,000 MTs).

Source: Authors, from this study.

The projected demand for maize as food and feed within the regions is illustrated following (Fig 6, panels a and b). Total maize demand as food is projected to increase from 5.21 million MT to 12.35 million MT, representing a 137 percent increase between 2015 and 2030. Zambia and Mozambique are projected to have the highest expansions in maize demand as food ( 251 and 205 percent, respectively). Maize food demand in Malawi, which is already a high maize-consuming country is projected to increase by 70 percent over the period. On the other hand, its maize feed demand increases by 217 percent, according to the projections. More generally in the region, the demand for maize as livestock feed grows faster than its demand as food. 


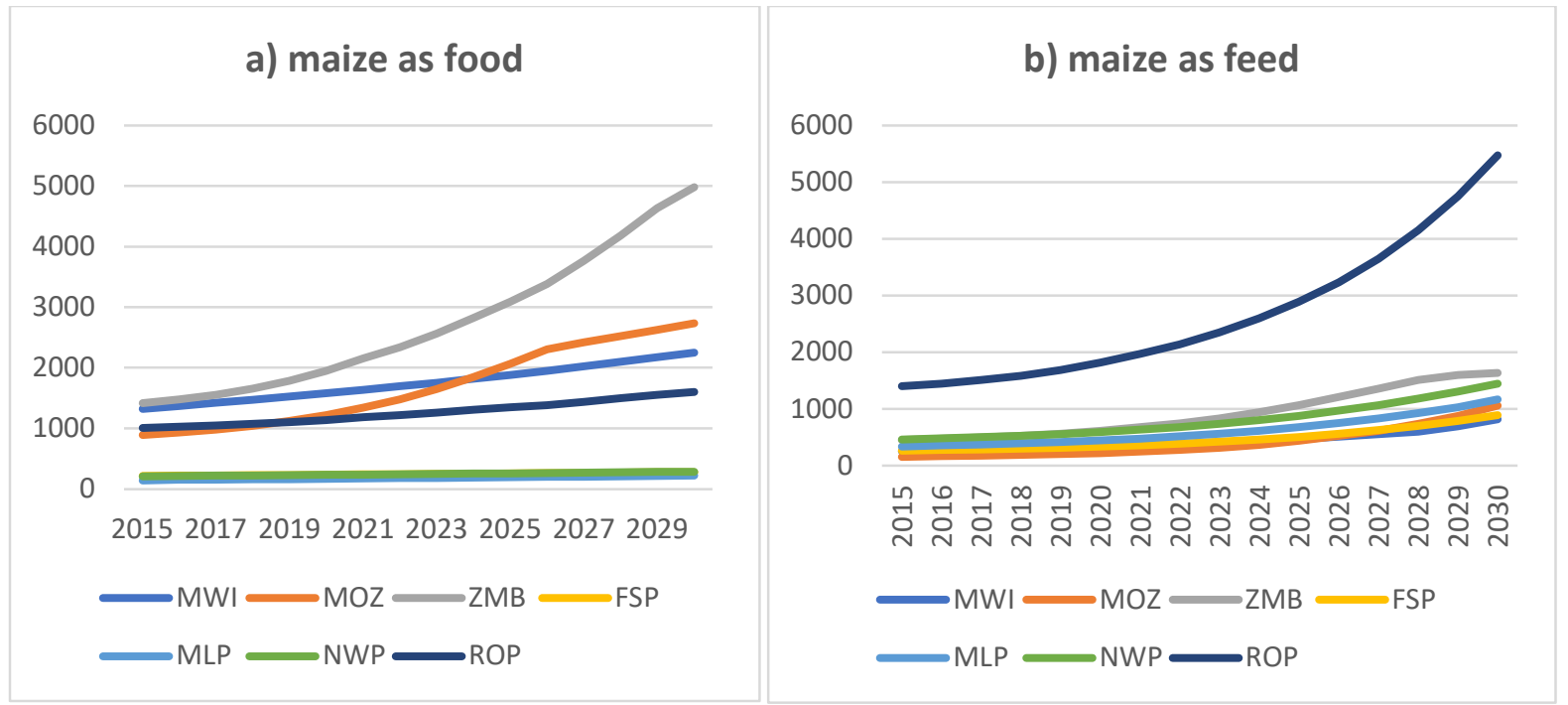

Fig. 6: Projections of demand for maize as a) food and b) feed in the study region under a business-asusual scenario, 2015 - 2030 (1,000 MTs).

Source: Authors, from this study.

Local chicken meat supply within the region is projected to increase from 832.16 thousand MT in 2015 to 8.14 million MT in 2030 while broiler meat supply increases from 1.33 million MTs to 11.76 million MT, representing a 787 percent increase. On the other hand, egg supply is projected to increase by 58 percent from 254.83 thousand MT in 2015 to 389.18 thousand MT in 2030 (Fig. 7).

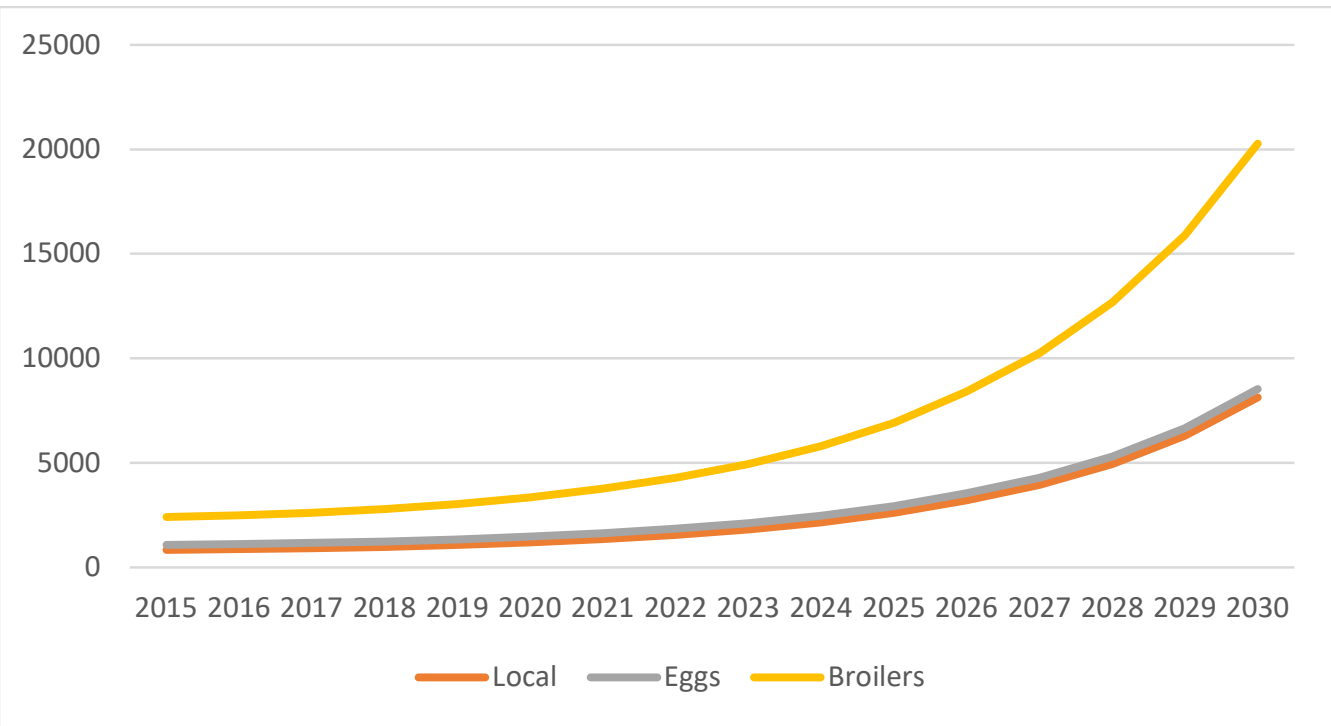

Fig. 7: Projections of local chicken, broiler meat, and egg supply in the study region under a businessas-usual scenario, $2015-2030$ (1,000 MTs).

Source: Authors, from this study. 
Base year simulation of the total supply of maize (for both food and feed use) increases from 9.73 million MT to 111 million MT between the period 2015 to 2030 (Figure 8). Compared to a projected total demand of 24.85 million MT of maize in 2030 , the results thus indicate a net producer position for the region in 2030.

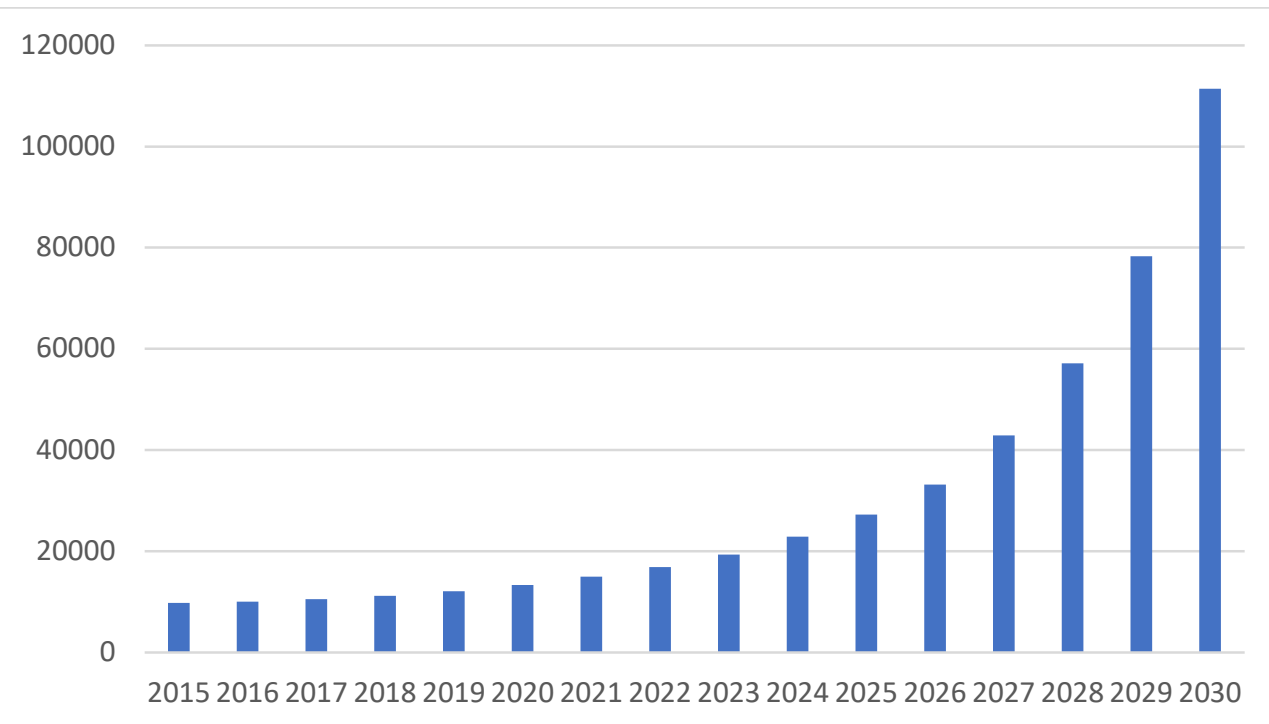

Fig. 8: Projections of maize supply in the study region under a business-as-usual scenario, 2015 - 2030 (1,000 MTs).

Source: Authors, from this study.

Drought conditions are projected to have impacts on regional food and feed availability and competition. The supply of local chicken decreases in Zambia by up to 3 percent (Fig. 9, panel a). The climate change scenario in addition results in marginal increases in the supply of local chicken meat in the other countries. The change in supply of chicken meat will however be lower in South Africa than in Mozambique or Malawi, with the highest positive changes projected for Mozambiqiue. Earlier studies have similarly shown mixed impacts of climate change in the southern Africa region, where changes in temperature and precipitation could lead to lower crop yields in some biomes in the region, but increase biomass yields in others (Lawal, Lennard, and Hewitson 2019).

Under the climate-induced drought, changes in broiler meat supply are smaller compared to projected changes in the supply of local chicken meat (Fig. 9, panel b). Zambia is in addition projected to experience a decrease in supply of broiler meat throughout the period 2015-2030. The other countries instead see increased supply of local chicken but at a slower pace. Drought conditions similarly impact on the supply of eggs within the sub-region as shown in Fig. 9, panel c. Apart from Zambia, the countries in the study are projected to see increased supply of eggs. The increase in egg supply will be most significant in Mozambique followed by Malawi and then South Africa, as shown. 
a) local chicken meat

\section{$2.00 \%$}

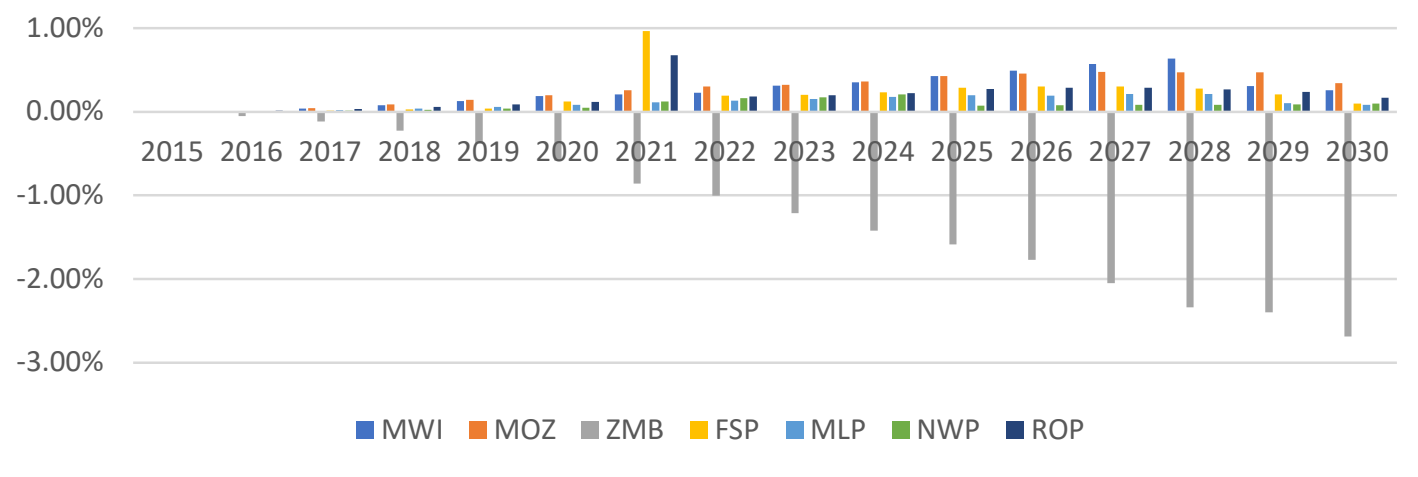

b) broiler meat

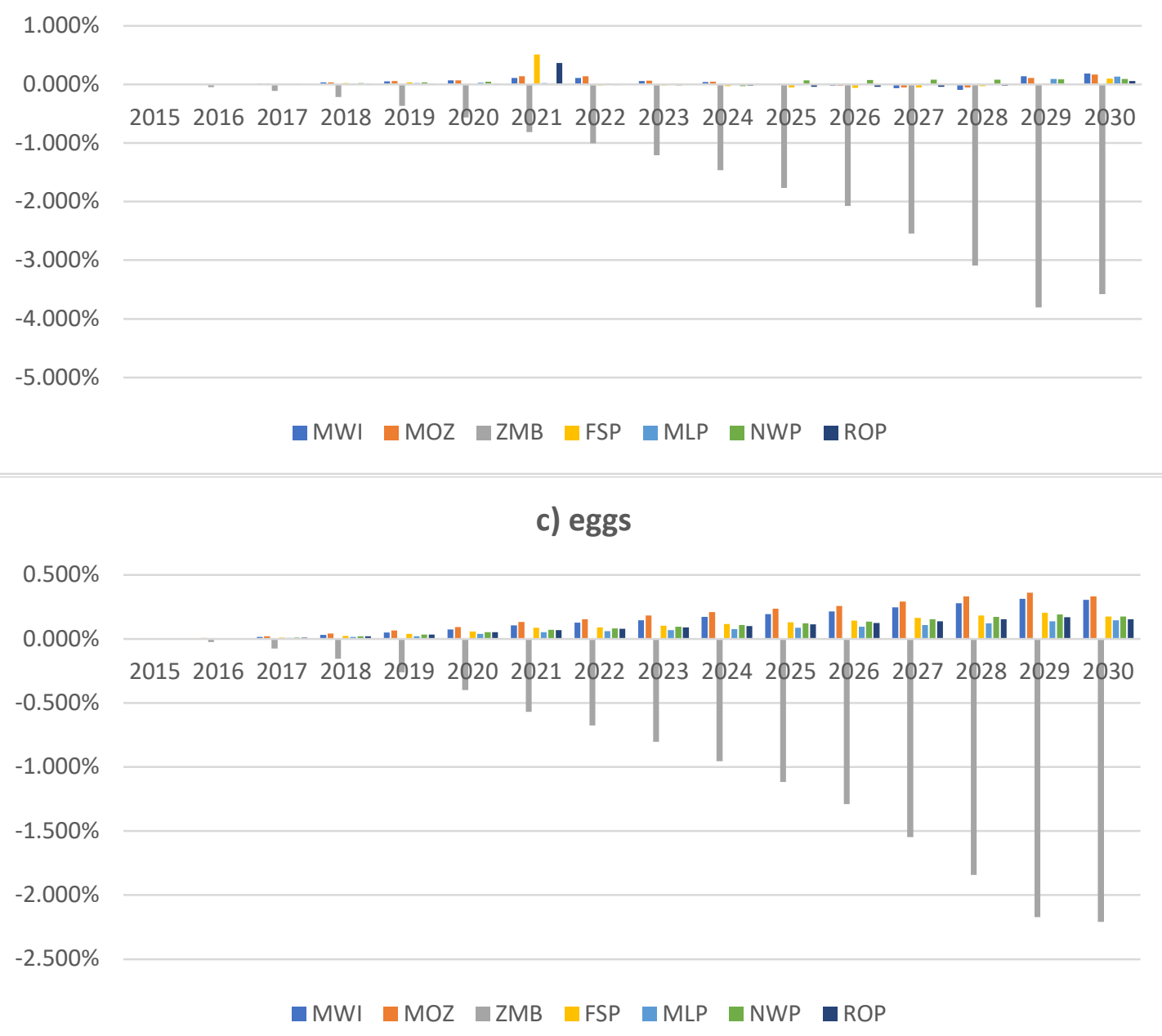

Fig. 9: Projections of changes in supply of a) local chicken b) broiler meat and c) eggs under climateinduced droughts, 2015 - 2030 (annual change from business-as-usual estimates).

Source: Authors, from this study. 
The observed changes could reflect differences in interactions of the market-driven and biophysical factors (e.g., crop and livestock shocks) thet result in diverging supply outcomes in the different countries. If these hold, a direct implication for the study countries is that there may be substantial scope to maintain food and feed supply in any one country through moving climate-affected products from areas experiencing surplus to others with deficit. Commercial trade remains a potential vehicle for achieving such transfers, and could apply to livestock animals (not modeled directly in this study), livestock-derived food products, livestock feeds, and human food. The changes from drought conditions are noted to lead to less than 1 percent increase in supply in the countries experiencing positive impacts of climate change, but up to 4 percent annual decreases in supply (in Zambia) where the impacts are negative. If these results hold true, they would suggest real incentives, at least on the part of Zambia, to pursue a regional rather than individual country approach to addressing the impacts of drought on the livestock sector.

Similar outcomes are observed for the supply of maize under climate change (as shown in Figure 10), where Zambia again experiences decreased annual supply compared to the baseline expectations. The other countries in the sub-region see (marginal) increases in supply compared to the baseline situation.

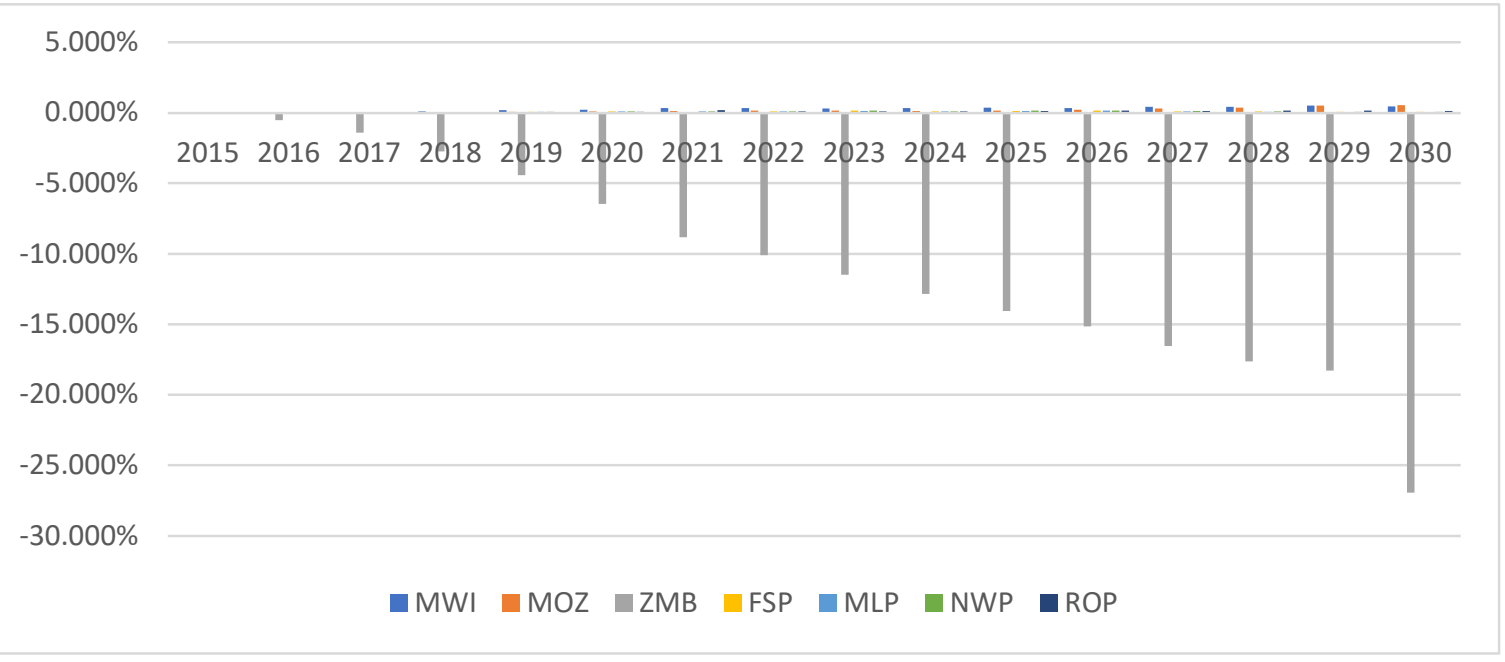

Fig. 10: Projections of changes in supply of maize under climate-induced droughts, 2015 - 2030 (annual percentage change from business-as-usual estimates).

Source: Authors, from this study.

The competition for maize as human food and livestock feed seems to increase over time in the region as the demand increases for both modelled components of crop use. This competition seems keener under drought conditions to 2030. In Fig. 11, we present the ratio of maize feed demand to maize food demand over time in the study countries. The ratio being less than unit (1) will indicate that the demand for maize as food exceeds its demand as livestock feed. From the model simulations, this is the case for most years. On the other hand, a ratio higher than one will indicate higher feed than food use of maize. As observed in the context-setting for this analysis using historical data, South Africa has a particularly high rate of livestock feed use (in commercial broiler production) as seen in Fig. 11, panel a. Its size and economic 
position in the region further means that it drives the regional-level observations on feed and food use in this direction (Fig. 11, panel e). Frictionless trade in poultry products and maize across the region thus has the potential to ignore the high needs for maize as food in countries like Malawi, increasing the food-feed competition for maize in such countries.

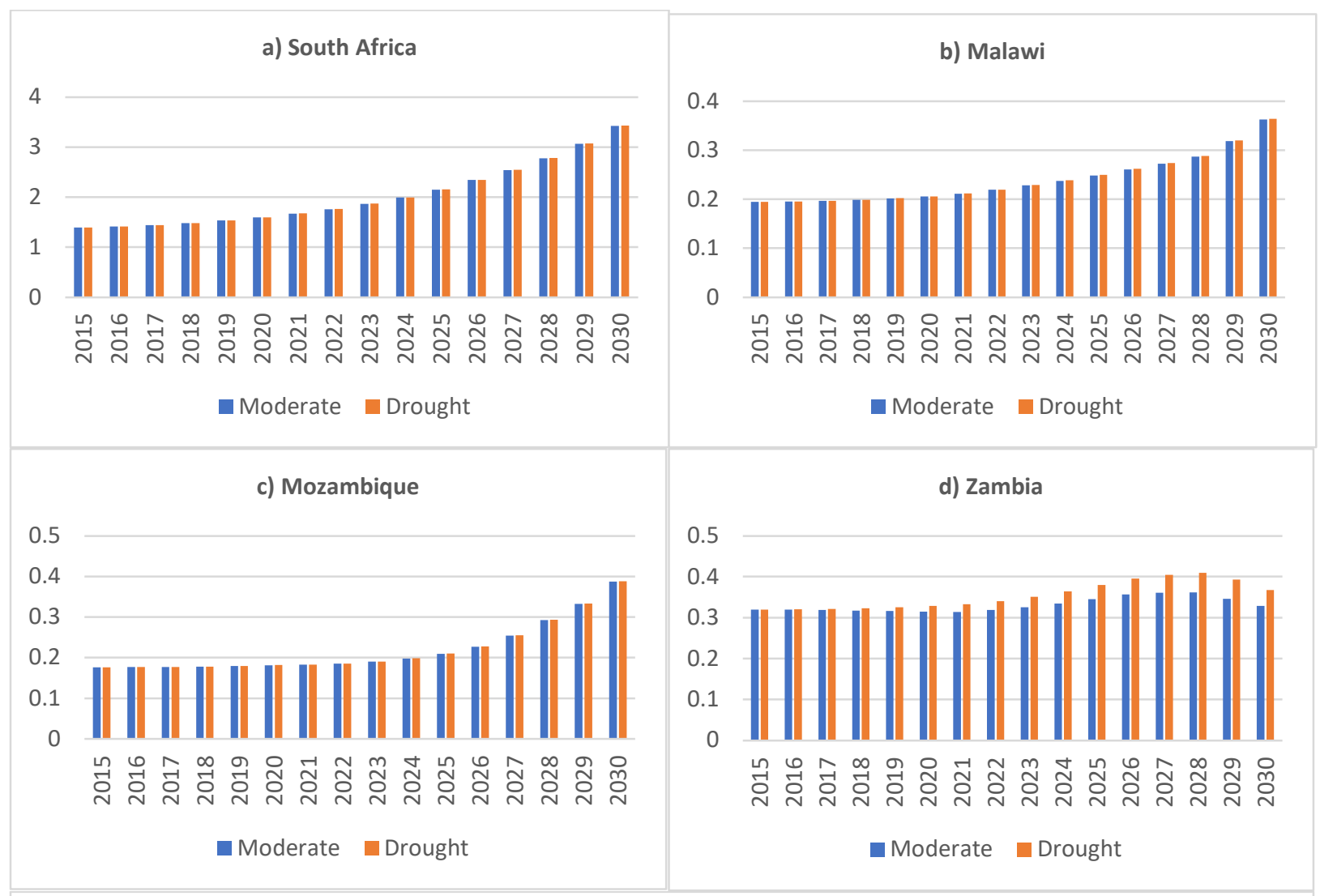

e) total region

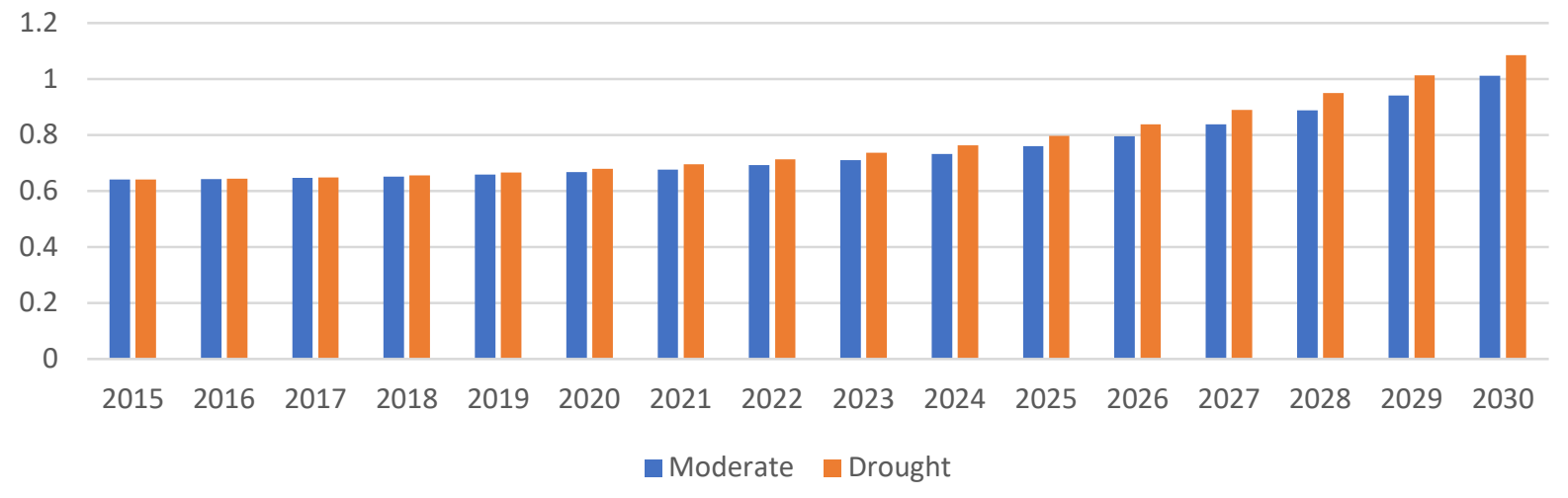

Fig. 11: Projections of livestock-to-household demand ratios for maize in a) South Africa b) Malawi c) Mozambique and d) Zambia and e) Region (total) under the moderate economic change or the business-as-usual scenario, and climate change, 2015- 2030.

Source: Authors, from this study. 
According to the model projections to 2030 , i.e., by when when population, income, and the demand for poultry meat increase the most in the model, the feed-food ratio for South Africa increases to 3.42, from around 1.4 in 2015. Although the ratio remains at less than one in Malawi, Mozambique and Zambia, we see over time, increased relative demand for maize as feed compared to food. The results derive from the earlier observations showing growing importance of livestock-derived foods in human diets across the region. In the case of Zambia, the results indicate that the demand for maize as livestock feeds will further increase relative to its demand as human food, under climate change.

An assessment of domestic prices showed reduced unit prices of chicken meat, eggs, and maize in the study countries over time compared to the starting year. In addition, product prices are projected to be higher under climate change than in the baseline simulation. While these results are consistent with the recurring narrative, i.e., that regionally coordinated markets lead to substantial increases in supply and to a net producer position regionally, we note that the scale of supply expansion leads to an unsustainable decline in prices. This issue will be addressed in follow-up work where aspects of the trade realities will be incorporated in the analytical model and additional (e.g., biophysical) constraints imposed on crop and livestock supply expansion. Additional work will also be done to validate the model's input and ouput data.

\section{Limitations of the study}

As with any other methodologies, the approach we have used for this study has some drawbacks that we discuss here. The elasticities we used have come from a variety of literature sources with the major task being to ensure their consistency with widely accepted economic principles. Although ours is a standard approach in foresight analysis (Sadoulet and de Janvry 1995), alongside, for example, approaches that derive elasticities econometrically using similar datasets from different countries, the use of secondary sources of elasticities is rather challenging to apply when increased levels of detail are required. Our study called for elasticites that were disaggregated along rural and urban distinctions, differentiated by products (e.g., traditional versus commercial broiler meat) and available at sub-national level (for South Africa). The data were not always available and some adjustments needed to be made (e.g., replicating elasticities for South Africa's sub-regions). Due to the absence of appropriate simulated data, we have also used similar of estimates to represent climate shocks in traditional and commercial systems, for example. In reality, traditional poultry systems may be more adversely impacted due to differences in management, particularly housing.

The model we have used forced the four countries in the study into trade in poultry products and maize with each other, but did not accommodate trade with the rest of the world. In addition, the model did not consider barriers to trade that exist between the countries beyond those imposed by distance, leaving out important as aspects of tariffs, trade regulations, and different exchange rate mechanisms. This construct was analytically convenient, allowing to demonstrate the impacts of a relatively frictionless livestock and maize trade across the region. It however affords the results of the study limited practical relevance to current policy. We relied in this study on the simulation of climate-induced global drought conditions using IMPACT (Robinson, Mason d'Croz, Islam, Cenacchi, et al. 2015) (Robinson, Mason d'Croz, Islam, Sulser, et al. 2015). Generally, the greenhouse gas emissions trends representative of long-term climate change have been quantified to 2100 (Riahi et al. 2017); and are only barely perceptible in IMPACT by 2030. As such, our regional model's time horizon of 15 years, from 2015 to 2030 did not provide much scope for climate modeling. 


\section{Conclusion}

There are indications that growth in the demand for livestock-derived foods will continue to grow in regions like Southern Africa, but not enough may be known about how such changes will impact on the competition for local livestock feed resources. In this study, we have used a partial equilibrium, multimarket model to quantify jointly, interactions of the poultry and maize sectors in South Africa, Malawi, Mozambique and Zambia. We have treated these countries as a hypothetical trading bloc, seeking insights into the potential role of livestock product and feed markets in addressing the cross-boundary challenge related to higher demand for livestock derived foods and crop biomass use. Given the importance of climate change as a key driver of crop and livestock sector changes in our selected southern Africa region, we introduce local climate change effects (in this case drought conditions) as the context for poultry and maize sector market dynamics. Our results indicate that frictionless trade between the study countries positions the countries to respond faster to the growth in demand for livestock-derived foods, helping to eliminate across the region needs for livestock product inflows from outside the region. The regional approach to livestock-related markets is advantageous to at least one study country in overcoming negative impacts deriving from climate change. The results of our study will suggest that some countries could experience climate change in magnitudes quite distinct from other countries in the region, giving them greater incentives to pursue regional rather than individual-country approaches to livestock market and trade development. However, these results are based on a specific, single climate scenario from a linked global economic model and do not incorporate a robust-enough framework to inform specific regional strategies. Additional work is needed to refine the analytical methods and data to better support policy in southern Africa or other regions with the potential and aspirations for coordinated agricultural and livestock sector development. Priority areas for future work will be to update the model specifications and input data to better capture livestock trade and climate dynamics of the study region.

\section{References}

Alonso, S., P. Dominguez-Salas, and D. Grace. 2019. "The Role of Livestock Products for Nutrition in the First 1,000 Days of Life." Animal Frontiers 9(4):24-31.

Andersson, M. S., A. Saltzman, P. Virk, and W. Pfeiffer. 2017. "Progress Update: Crop Development of Biofortified Staple Food Crops under HarvestPlus." African Journal of Food, Agriculture, Nutrition and Development 17:11905-11935.

Bahta, S., D. Enahoro, K. M. Rich, A. Notenbaert, K. Waha, J. Mukiri, and B. Paul. 2020. "Progress Report on Livestock Master Plan Modelling Innovations. Nairobi, Kenya: ILRI."

Baltenweck, Isabelle, Dolapo Enahoro, Aymen Frija, and Shirley Tarawali. 2020. "Why Is Production of Animal Source Foods Important for Economic Development in Africa and Asia?" Animal Frontiers. Doi: 10.1093/Af/Vfaa036.

CSO. 2015. Price, Imports, Exports, Vol 1522015 The Monthly. December. Central Statistical Office, Zambia. CSO: Zambia.

DAFF. 2017. A Profile of SOuth African Broiler Market Value Chain. Department of Agriculture, Forestry \& Fisheries. 
Delgado, C., M. Rosegrant, H. Steinfeld, S. Ehui, and C. Courbois. 2001. "Livestock to 2020: The Next Food Revolution." Outlook on Agriculture 30(1):27-29. doi: 10.5367/000000001101293427.

Dzama, K. 2016. Is the Livestock Sector in Southern Africa Prepared for Climate Change? SAIIA Policy Briefing 153, South African Institute of International Affairs. SAlIA: South Africa.

Enahoro, D., J. Sircely, R. B. Boone, S. Oloo, A. M. Komarek, S. Bahta, Mario Herrero, and K. M. Rich. 2021. Feed Biomass Production May Not Be Sufficient to Support Emerging Livestock Demand. 184. Pretoria, South Africa.

Enahoro, Dolapo, Mats Lannerstad, Catherine Pfeifer, and Paula Dominguez-Salas. 2018a. "Contributions of Livestock-Derived Foods to Nutrient Supply under Changing Demand in Low- and Middle-Income Countries." Global Food Security 19:1-10. doi: 10.1016/j.gfs.2018.08.002.

Enahoro, Dolapo, Mats Lannerstad, Catherine Pfeifer, and Paula Dominguez-Salas. 2018b.

"Contributions of Livestock-Derived Foods to Nutrient Supply under Changing Demand in Low- and Middle-Income Countries." Global Food Security 19:1-10. doi: 10.1016/j.gfs.2018.08.002.

FAO-GIEWS. 2020. Global Information and Early Warning System on Food and Agriculture. GIEWS Country Brief: Mozambique. FAO: Rome.

FAO-GIEWS. 2021. Global Information and Early Warning System on Food and Agriculture. GIEWS Country Brief: Malawi. FAO: Rome.

FAO-WFP. 2019. Crop and Food Security Assessment Mission to Mozambique. The Food and Agricultural Organization \& World Food Program. FAO/WFP: Rome.

FAO. 2015. Monthly Report on Food Price Trends. Food and Agricultural Organization. FAO: Rome.

FAO. 2018. Food Security and Nutrition in the World the State of Building Climate Resilience for Food Security and Nutrition. FAO: Rome.

FAO. 2020. "FAOSTAT Database, Food and Agriculture Organization of the United Nations (FAO). Website Accessed on [31/08/2020]."

FEWSNET. 2018. Mozambique Staple Food Market Fundamentals 2018.

Fukase, Emiko, and Will Martin. 2020. "Economic Growth, Convergence, and World Food Demand and Supply." World Development 132:104954. doi: 10.1016/j.worlddev.2020.104954.

GAIN. 2017. Grain and Feed Annual - SOuth Africa. Global Agricultural Information Network.

Herrero, M., D. Grace, J. Njuki, N. Johnson, D. Enahoro, S. Silvestri, and M. Rufino. 2013. "The Roles of Livestock in Developing Countries: The Good, the Bad and the Knowledge Gaps." Animal 7(s1):318.

Herrero, Mario, Petr Havlík, John McIntire, Amanda Palazzo, and Hugo Valin. 2014. African Livestock Futures: Realizing the Potential of Livestock for Food Security, Poverty Reduction and the Environment in Sub-Saharan Africa. Geneva, Switzerland.

Hoffman, A. L., A. R. Kemanian, and C. .. Forest. 2018. "Analysis of Climate Signals in the Crop Yield Record of Sub-Saharan Africa." Global Change Biology 24:143-57.

Homann-Kee Tui, Sabine, Andre Van Rooyen, and Isaac Minde. 2011. National and Regional Livestock 
Markets: Opportunities for Growth in SADC. Information Brief.

ILRI. 2019. "Options for the Livestock Sector in Developing and Emerging Economies to 2030 and Beyond." Meat: The Future Series. Geneva, Switzerland: World Economic Forum.

Instituto Nacional de Estatística. 2017. DIVULGAÇÃO OS RESULTADOS PRELIMINARES - CENSUO 2017. Instituto Nacional de Estatística: Mozambique.

IUCN. 2010. Building Climate Change Resilience for African Livestock in Sub-Saharan Africa - World Initiative for Sustainable Pastoralism (WISP): A Program of IUCN - The International Union for Conservation of Nature, Eastern and Southern Africa Regional Office. IUCN: Nairobi.

Komarek, Adam M., Shahnila Dunston, Dolapo Enahoro, H. Charles J. Godfray, Mario Herrero, Daniel Mason-D'Croz, Karl M. Rich, Peter Scarborough, Marco Springmann, Timothy B. Sulser, Keith Wiebe, and Dirk Willenbockel. 2021. "Income, Consumer Preferences, and the Future of LivestockDerived Food Demand." Global Environmental Change 70:102343. doi: https://doi.org/10.1016/j.gloenvcha.2021.102343.

Lapar, L., E. Ouma, P. Lule, Nguyen Que, Dang Khoi, and K. Rich. 2018. "Application of a Multi-Market Partial Equilibrium Model in the Pig Sector of Vietnam and Uganda. Presented at the ICAE PIM PreConference Workshop on Rural Transformation in the 21st Century: The Challenges of LowIncome, Late-Transforming Countries, Vanc."

Latino, L. R., U. Pica-Ciamarra, and D. Wisser. 2020. "Africa: The Livestock Revolution Urbanizes." Global Food Security 26.

Lawal, Shakirudeen, Christopher Lennard, and Bruce Hewitson. 2019. "Response of Southern African Vegetation to Climate Change at 1.5 and $2.0^{\circ}$ Global Warming above the Pre-Industrial Level." Climate Services 16(September):100134. doi: 10.1016/j.cliser.2019.100134.

Mafongoya, Paramu L., Kabir Peerbhay, Obert Jiri, and Nhamo Nhamo. 2017. "Climate Scenarios in Relation to Agricultural Patterns of Major Crops in Southern Africa." Pp. 21-37 in Smart Technologies for Sustainable Smallholder Agriculture, edited by N. Nhamo, D. Chikoye, and T. B. T.S. T. for S. S. A. Gondwe. Elsevier.

Matope, A., T. J. Zindove, M. Dhliwayo, and M. Chimonyo. 2019. "Mitigating the Effects of Drought on Cattle Production in Communal Rangelands of Zimbabwe." Tropical Animal Health and Production $1-10$.

Mottet, Anne, Cees de Haan, Alessandra Falcucci, Giuseppe Tempio, Carolyn Opio, and Pierre Gerber. 2017. "Livestock: On Our Plates or Eating at Our Table? A New Analysis of the Feed/Food Debate." Global Food Security 14(January 2016):1-8. doi: 10.1016/j.gfs.2017.01.001.

NAMC. 2017. The South African Food Cost Review. National Agricultural Marketing Council. NAMC: South Africa.

NSO. 2016. Statistical Yearbook 2016. National Statistical Office, Malawi.

NSO. 2019a. 2018 Malawi Population and Housing Main Report. National Statistical Office. Malawi.

NSO. 2019b. Trade Statistics Brief Release. National Statistical Office. Malawi. NSO: Malawi.

NSO. 2020. Population Projections, 2018 -2050. National Statistical Office. Malawi. NSO: Malawi. 
Pica-Ciamarra, Ugo, and Joachim Otte. 2011. "The 'Livestock Revolution': Rhetoric and Reality." Outlook on Agriculture 40(1):7-19. doi: 10.5367/oa.2011.0030.

Popkin, B. M. 2004. "The Nutrition Transition: An Overview of World Patterns of Change." Nutrition Reviews 62:S140-43.

Randolph, T. F., E. Schelling, D. Grace, C. F. Nicholson, J. L. Leroy, D. C. Cole, M. W. Demment, A. Omore, J. Zinsstag, and M. Ruel. 2007. "Role of Livestock in Human Nutrition and Health for Poverty Reduction in Developing Countries." Invited Review: Journal of Animal Science 85(11):2788-2800.

Riahi, Keywan, Detlef P. van Vuuren, Elmar Kriegler, Jae Edmonds, Brian C. O'Neill, Shinichiro Fujimori, Nico Bauer, Katherine Calvin, Rob Dellink, Oliver Fricko, Wolfgang Lutz, Alexander Popp, Jesus Crespo Cuaresma, Samir KC, Marian Leimbach, Leiwen Jiang, Tom Kram, Shilpa Rao, Johannes Emmerling, Kristie Ebi, Tomoko Hasegawa, Petr Havlik, Florian Humpenöder, Lara Aleluia Da Silva, Steve Smith, Elke Stehfest, Valentina Bosetti, Jiyong Eom, David Gernaat, Toshihiko Masui, Joeri Rogelj, Jessica Strefler, Laurent Drouet, Volker Krey, Gunnar Luderer, Mathijs Harmsen, Kiyoshi Takahashi, Lavinia Baumstark, Jonathan C. Doelman, Mikiko Kainuma, Zbigniew Klimont, Giacomo Marangoni, Hermann Lotze-Campen, Michael Obersteiner, Andrzej Tabeau, and Massimo Tavoni. 2017. "The Shared Socioeconomic Pathways and Their Energy, Land Use, and Greenhouse Gas Emissions Implications: An Overview." Global Environmental Change 42:153-68. doi: http://dx.doi.org/10.1016/j.gloenvcha.2016.05.009.

Rich, Karl M., and Alex Winter-Nelson. 2007. "An Integrated Epidemiological-Economic Analysis of Foot and Mouth Disease: Applications to the Southern Cone of South America." American Journal of Agricultural Economics 89(3):682-97. doi: 10.1111/j.1467-8276.2007.01006.x.

Robinson, Sherman, Daniel Mason d'Croz, Shahnila Islam, Nicola Cenacchi, Bernardo Creamer, Arthur Gueneau, Guy Hareau, Ulrich Kleinwechter, Khondoker Mottaleb, Swamikannu Nedumaran, Richard D. Robertson, Mark W. Rosegrant, Gbegbelegbe Sika, Timothy B. Sulser, and Keith D. Wiebe. 2015. Climate Change Adaptation in Agriculture: Ex Ante Analysis of Promising and Alternative Crop Technologies Using DSSAT and IMPACT. 01469. Washington, D.C.

Robinson, Sherman, Daniel Mason d'Croz, Shahnila Islam, Timothy B. Sulser, Richard D. Robertson, Tingju Zhu, Arthur Gueneau, Gauthier Pitois, and Mark W. Rosegrant. 2015. The International Model for Policy Analysis of Agricultural Commodities and Trade (IMPACT): Model Description for Version 3. 1483. Washington, DC.

Robinson, T. P., P. K. Thornton, G. Franceschini, R. L. Kruska, F. Chiozza, A. Notenbaert, G. Cecchi, M. Herrero, M. Epprecht, S. Fritz, L. You, G. Conchedda, and L. See. 2011. Global Livestock Production Systems. Rome: Food and Agriculture Organization of the United Nations (FAO) and International Livestock Research Institute(ILRI).

Rosegrant, Mark W., Simla Tokgoz, and Prapti Bhandary. 2013. "The New Normal? A Tighter Global Agricultural Supply and Demand Relation and Its Implications for Food Security." American Journal of Agricultural Economics 95(2):303-9. doi: 10.1093/ajae/aas041.

SADC. 2006. Regional Indicative Strategic Development Plan (RISDP). Southern African Developmnt Community. SADC: Gaborone, Botswana.

Sadoulet, E., and A. de Janvry. 1995. Quantitative Development Policy Analysis. Baltimore, USA: John Hopkins University Press. 
Santpoort, R. 2020. "The Drivers of Maize Area Expansion in Sub-Saharan Africa. How Policies to Boost Maize Production Overlook the Interests of Smallholder Farmers." Land 9(68).

SAPA. 2017. Distributions of Chickens in South Africa. South African Poultry Association. SAPA: South Africa.

SAPA. 2019. 2019 Industry Profile. South African Poultry Association. SAPA: South Africa.

Shiferaw, Bekele, BoddupalliM. Prasanna, Jonathan Hellin, and Marianne Bänziger. 2011. "Crops That Feed the World. Past Successes and Future Challenges to the Role Played by Maize in Global Food Security." Food Security 3(3):307-27. doi: 10.1007/s12571-011-0140-5.

Statista. 2021. Per Capita Consumption of Meat in South Africa from 2010 to 2017. Available at Https://Www.Statista.Com/Statistics/963216/per-Capita-Consumption-of-Meat-by-Type-SouthAfrica/.

Statssa. 2014. Living Conditions of Households in South Africa. Statistics South Africa. Statssa: South Africa.

Taha, F. A., and W. F. Hahn. 2015. "No Title." International Food and Agribusiness Management Review 18(SI A).

Thornton, P. K. 2010. "Livestock Production: Recent Trends, Future Prospects." Philosophical Transactions of the Royal Society B: Biological Sciences 365(1554):2853-67. doi: 10.1098/rstb.2010.0134.

Thornton, P. K., and P. J. Gerber. 2010. "Climate Change and the Growth of the Livestock Sector in Developing Countries." Mitigation and Adaptation Strategies for Global Change 15(2):169-84. doi: 10.1007/s11027-009-9210-9.

Thornton, P. K., J. van de Steeg, A. Notenbaert, and M. Herrero. 2009. "The Impacts of Climate Change on Livestock and Livestock Systems in Developing Countries: A Review of What We Know and What We Need to Know." Agricultural Systems 101(3):113-27. doi: 10.1016/j.agsy.2009.05.002.

Tui, Sabine Homann-Kee, André F. van Rooyen, and Isaac Mninde. 2006. “National and Regional Livestock Markets : Opportunities for Growth in SADC. Documentation. International Crops Research Institute for the Semi-Arid Tropics, Patancheru, Andhra Pradesh, India." 


\section{Appendix}

Appendix Table 1: Simulated world prices of maize, chicken meat and eggs under baseline and drought conditions to 2030

\begin{tabular}{llllllll}
\multicolumn{4}{c}{ Maize } & \multicolumn{2}{c}{ Chicken Meat } & \multicolumn{2}{c}{ Eggs } \\
\hline & $\underline{\text { Baseline }}$ & $\underline{\text { Drought }}$ & $\underline{\text { Baseline }}$ & $\underline{\text { Drought }}$ & $\underline{\text { Baseline }}$ & $\underline{\text { Drought }}$ \\
2015 & 0.00000 & 0.00000 & 0.00000 & 0.00000 & 0.00000 & 0.00000 \\
2016 & 0.00633 & 0.00633 & 0.00388 & 0.00388 & 0.00442 & 0.00442 \\
2017 & 0.00961 & 0.00996 & 0.01133 & 0.01176 & 0.01088 & 0.01094 \\
2018 & 0.00981 & 0.01009 & 0.01109 & 0.01140 & 0.01079 & 0.01082 \\
2019 & 0.01002 & 0.01025 & 0.01085 & 0.01108 & 0.01070 & 0.01070 \\
2020 & 0.01026 & 0.01045 & 0.01066 & 0.01085 & 0.01060 & 0.01060 \\
2021 & 0.00943 & 0.00958 & 0.00913 & 0.00929 & 0.00827 & 0.00826 \\
2022 & 0.01665 & 0.01666 & 0.01035 & 0.01038 & 0.00814 & 0.00814 \\
2023 & 0.01702 & 0.01703 & 0.01007 & 0.01010 & 0.00800 & 0.00800 \\
2024 & 0.01736 & 0.01737 & 0.00977 & 0.00981 & 0.00784 & 0.00784 \\
2025 & 0.01379 & 0.01381 & 0.00947 & 0.00950 & 0.00751 & 0.00752 \\
2026 & 0.01204 & 0.01206 & 0.00825 & 0.00829 & 0.00557 & 0.00557 \\
2027 & 0.01265 & 0.01266 & 0.01124 & 0.01127 & 0.00530 & 0.00530 \\
2028 & 0.01156 & 0.01158 & 0.01096 & 0.01100 & 0.00506 & 0.00506 \\
2029 & 0.01044 & 0.01046 & 0.01068 & 0.01071 & 0.00482 & 0.00482 \\
2030 & 0.00933 & 0.00935 & 0.01043 & 0.01046 & 0.00458 & 0.00458 \\
\hline
\end{tabular}

Source: IMPACT model input data under moderate economic growth, constant 2005 climate (Baseline), and moderate growth,

climate change (Drought) scenarios (Robinson et al., 2015). 
Appendix Table 2: Projections of own-price elasticities of food demand, from 2015 to 2025

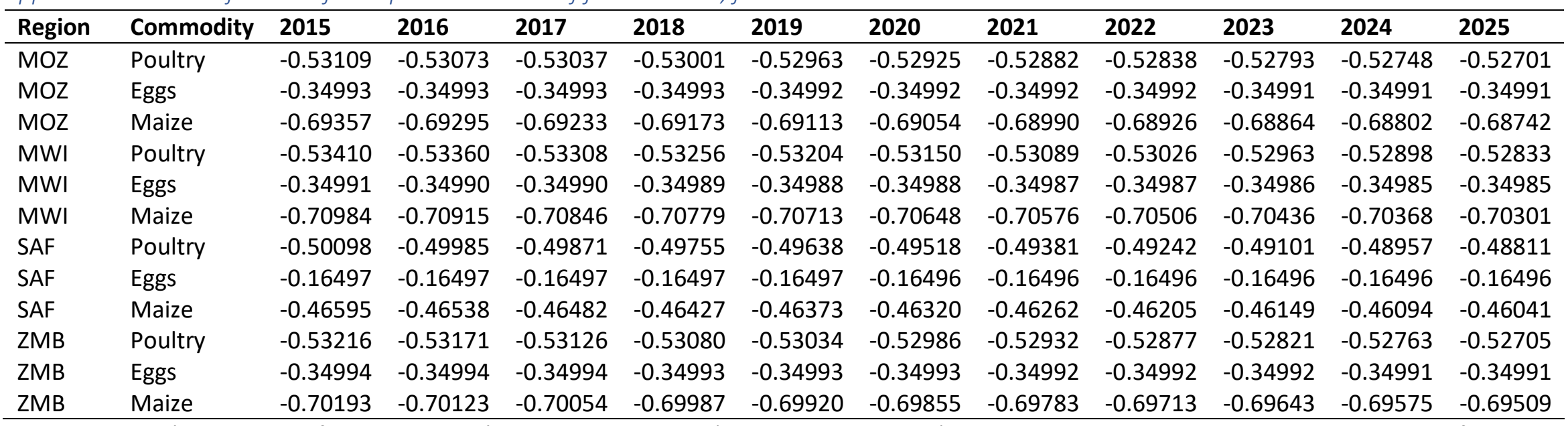

Source: Authors' adaptation of IMPACT model's baseline input data (Robinson et al., 2015). MWI: Malawi; MOZ: Mozambique; SAF: South Africa (applied to South Africa's four regions); ZMB: Zambia. Elasticities for Poultry refer to poultry meat from Traditional Chicken and Commercial Broiler systems. Equivalent values were used for urban and rural elasticities. Only the first 11 years of the 16-year data trend used are here presented. 
Appendix Table 3: Projections of income elasticites of food demand, from 2015 to 2025

\begin{tabular}{|c|c|c|c|c|c|c|c|c|c|c|c|c|}
\hline Region & Commodity & 2015 & 2016 & 2017 & 2018 & 2019 & 2020 & 2021 & 2022 & 2023 & 2024 & 2025 \\
\hline MOZ & Poultry & .357257 & 0.356546 & 0.355822 & 0.355088 & 0.354342 & 0.353583 & 0.352718 & 0.351838 & 0.350942 & 0.350029 & 0.349101 \\
\hline $\mathrm{MOZ}$ & Eggs & 349821 & 0.349816 & .349811 & 0.349806 & 0.3498 & 0.349795 & 0.349789 & 0.349783 & 0.349777 & 0.349771 & 0.349765 \\
\hline MOZ & Maize & 212109 & .21086 & 0.209631 & 0.20842 & 0.207229 & 0.206056 & 0.204762 & 0.203491 & 0.202243 & 0.201016 & \\
\hline MWI & Poultry & 0.551677 & 0.55067 & 0.549648 & 0.548609 & 0.547553 & 0.54648 & 0.545256 & 0.54401 & 0.542741 & 0.541449 & 0.540134 \\
\hline MWI & Eggs & 349769 & 0.349756 & 744 & 0.349732 & 34972 & 0.349708 & 0.349695 & 683 & 967 & 658 & 646 \\
\hline MWI & Maize & 0.108833 & 0.107446 & 0.106081 & 0.104737 & 0.103414 & 0.102112 & 0.100675 & 0.099263 & 0.097876 & 513 & 0.095173 \\
\hline SAF & Poultry & 0.47705 & 0.4748 & 0.472516 & 0.470198 & 0.467844 & 0.465456 & 0.462718 & 0.459935 & 0.457106 & 0.454232 & 0.451311 \\
\hline SAF & Eggs & -0.04006 & -0.04007 & -0.04007 & -0.04007 & -0.04008 & -0.04008 & -0.04008 & -0.04009 & -0.04009 & -0.04009 & -0.0401 \\
\hline SAF & Maize & 0.013809 & 0.012665 & 0.011543 & 0.010443 & 0.009365 & 0.008307 & 0.007138 & 0.005995 & 0.004877 & 0.003784 & 0.002715 \\
\hline ZMB & Poultry & 0.653084 & 0.652197 & 0.651295 & 0.650378 & 0.649445 & 0.648496 & 0.647412 & 0.646308 & 0.645183 & 0.644036 & 0.642867 \\
\hline ZMB & Eggs & 0.349795 & 0.349789 & 0.349783 & 0.349777 & 0.34977 & 0.349764 & 0.349756 & 0.349749 & 0.349741 & 0.349734 & 0.349726 \\
\hline $\mathrm{ZMB}$ & Maize & 0.209529 & 0.20813 & 0.206755 & 0.205403 & 0.204074 & 0.202768 & 0.201329 & 0.199918 & 0.198533 & 0.197175 & 0.195842 \\
\hline
\end{tabular}

Source: Authors' adaptation of IMPACT model's baseline input data (Robinson et al., 2015). MWI: Malawi; MOZ: Mozambique; SAF: South Africa (applied to South Africa's four regions); ZMB: Zambia. Elasticities for Poultry refer to poultry meat from Traditional Chicken and Commercial Broiler systems. Equivalent values were used for urban and rural elasticies. Only the first 11 years of the 16-year data trend used are here presented. 
Appendix Table 4: Exogenous growth rate of Maize supply under baseline and drought conditions to 2025

\begin{tabular}{lllllllllllll}
\hline Scenario & Region & Location & 2016 & 2017 & 2018 & 2019 & 2020 & 2021 & 2022 & 2023 & 2024 & 2025 \\
\hline Baseline & MWI & Urban & 0.01522 & 0.01543 & 0.01549 & 0.01554 & 0.01561 & 0.01542 & 0.01770 & 0.01780 & 0.01789 & 0.01691 \\
Baseline & MOZ & Urban & 0.01617 & 0.01642 & 0.01648 & 0.01653 & 0.01660 & 0.01642 & 0.01862 & 0.01872 & 0.01881 & 0.01783 \\
Baseline & SAF & Urban & 0.00782 & 0.00811 & 0.00817 & 0.00823 & 0.00830 & 0.00817 & 0.01069 & 0.01079 & 0.01088 & 0.00988 \\
Baseline & ZMB & Urban & 0.01598 & 0.01622 & 0.01628 & 0.01634 & 0.01640 & 0.01628 & 0.01829 & 0.01839 & 0.01847 & 0.01753 \\
Baseline & MWI & Rural & 0.00814 & 0.00167 & 0.00178 & 0.00189 & 0.00202 & 0.00164 & 0.00449 & 0.00468 & 0.00487 & 0.00293 \\
Baseline & MOZ & Rural & 0.00904 & 0.00262 & 0.00273 & 0.00284 & 0.00297 & 0.00262 & 0.00535 & 0.00555 & 0.00573 & 0.00380 \\
Baseline & SAF & Rural & 0.00051 & -0.00495 & -0.00483 & -0.00470 & -0.00456 & -0.00482 & -0.00352 & -0.00332 & -0.00313 & -0.00510 \\
Baseline & ZMB & Rural & 0.00890 & 0.00242 & 0.00253 & 0.00265 & 0.00278 & 0.00253 & 0.00501 & 0.00520 & 0.00538 & 0.00352 \\
& & & & & & & & & & & & \\
Drought & $\mathrm{MWI}$ & Urban & 0.01522 & 0.01554 & 0.01557 & 0.01562 & 0.01567 & 0.01547 & 0.01770 & 0.01780 & 0.01790 & 0.01692 \\
Drought & $\mathrm{MOZ}$ & Urban & 0.01617 & 0.01653 & 0.01656 & 0.01660 & 0.01666 & 0.01647 & 0.01862 & 0.01872 & 0.01882 & 0.01784 \\
Drought & $\mathrm{SAF}$ & Urban & 0.00782 & 0.00819 & 0.00824 & 0.00829 & 0.00835 & 0.00821 & 0.01069 & 0.01079 & 0.01088 & 0.00989 \\
Drought & ZMB & Urban & 0.01598 & 0.01630 & 0.01635 & 0.01639 & 0.01645 & 0.01632 & 0.01829 & 0.01839 & 0.01848 & 0.01754 \\
Drought & $\mathrm{MWI}$ & Rural & 0.00814 & 0.00188 & 0.00195 & 0.00203 & 0.00214 & 0.00174 & 0.00449 & 0.00469 & 0.00487 & 0.00294 \\
Drought & $\mathrm{MOZ}$ & Rural & 0.00904 & 0.00283 & 0.00290 & 0.00298 & 0.00308 & 0.00272 & 0.00536 & 0.00556 & 0.00574 & 0.00381 \\
Drought & $\mathrm{SAF}$ & Rural & 0.00051 & -0.00479 & -0.00470 & -0.00460 & -0.00448 & -0.00475 & -0.00351 & -0.00331 & -0.00313 & -0.00509 \\
Drought & ZMB. & Rural & 0.00890 & 0.00258 & 0.00266 & 0.00275 & 0.00287 & 0.00261 & 0.00502 & 0.00521 & 0.00538 & 0.00353 \\
\hline
\end{tabular}

Source: Authors' adaptations of IMPACT model input data under moderate economic growth, constant 2005 climate (Baseline), and moderate growth, climate change (Drought) scenarios (Robinson et al., 2015). MWI: Malawi; MOZ: Mozambique; SAF: South Africa (applied to South Africa's four regions); ZMB: Zambia. Only the first 11 years of the 16-year data trend used are here presented. 
Appendix Table 5: Exogenous growth rate of Poultry Meat and Egg supply under baseline and drought conditions to 2025

\begin{tabular}{|c|c|c|c|c|c|c|c|c|c|c|c|c|}
\hline Scenario & Commodity & Region & 2016 & 2017 & 2018 & 2019 & 2020 & 2021 & 2022 & 2023 & 2024 & 2025 \\
\hline Baseline & Meat & MLW & 0.016743 & 0.01022 & 0.010136 & 0.01005 & 0.009975 & 0.009595 & 0.007088 & 0.006982 & 0.006874 & 0.006981 \\
\hline Baseline & Meat & MOZ & 0.018311 & 0.011752 & 0.011668 & 0.011582 & 0.011507 & 0.011126 & 0.008435 & 0.008329 & 0.008221 & 0.008328 \\
\hline Baseline & Meat & SAF & 0.017995 & 0.013238 & 0.013151 & 0.01306 & 0.012974 & 0.012802 & 0.00986 & 0.009734 & 0.009604 & 0.009845 \\
\hline Baseline & Meat & ZAM & 0.019905 & 0.013149 & 0.013068 & 0.012986 & 0.012914 & 0.012574 & 0.010005 & 0.009902 & 0.009797 & 0.009912 \\
\hline Baseline & Eggs & MLW & 0.012933 & 0.006333 & 0.006295 & 0.006256 & 0.006212 & 0.005564 & 0.004106 & 0.004041 & 0.003973 & 0.004087 \\
\hline Baseline & Eggs & MOZ & 0.013502 & 0.006863 & 0.006826 & 0.006786 & 0.006743 & 0.006095 & 0.004451 & 0.004386 & 0.004319 & 0.004433 \\
\hline Baseline & Eggs & SAF & 0.018807 & 0.014951 & 0.014936 & 0.014919 & 0.014 & 0.014735 & 3267 & 0.01 & 3209 & 3283 \\
\hline Baseline & Eggs & ZAM & 0.013267 & 0.006421 & 0.006385 & 0.006346 & 0.006302 & 0.005677 & 0.004161 & 0.004094 & 0.004026 & 0.004156 \\
\hline Drought & Meat & & & & & & & & & & & \\
\hline Drought & Meat & $\mathrm{MOZ}$ & & 0.011928 & & & & 0.011198 & & & & \\
\hline Drought & Meat & SAF & 0.017995 & 0.013322 & 0.013209 & 0.013103 & 0.013008 & 0.01283 & 0.009867 & 0.009741 & 0.009612 & 0.009852 \\
\hline Drought & Meat & ZAM & 0.019905 & 0.013288 & 0.013173 & 0.013068 & 0.012981 & 0.012631 & 0.010014 & 0.009912 & 0.009807 & 0.009922 \\
\hline Drought & Eggs & MLW & 0.012933 & 0.006332 & 0.006286 & 0.006243 & 0.006199 & 0.005553 & 0.004105 & 0.00404 & 0.003973 & 0.004087 \\
\hline Drought & Eggs & MOZ & 0.013502 & 0.006863 & 0.006817 & 0.006774 & 0.00673 & 0.006083 & 0.004451 & 0.004386 & 0.004319 & 0.004432 \\
\hline Drought & Eggs & SAF & 0.018807 & 0.014951 & 0.014938 & 0.014922 & 0.0149 & 0.014737 & 0.013266 & 0.013237 & 0.013207 & 0.013282 \\
\hline Drought & Eggs & ZAM & 0.013267 & 0.00641 & 0.006367 & 0.006326 & 0.006284 & 0.005661 & 0.00416 & 0.004094 & 0.004025 & 0.004155 \\
\hline
\end{tabular}

Source: Adaptation of IMPACT model's baseline input data (Robinson et al., 2015). MWI: Malawi; MOZ: Mozambique; SAF: South Africa (applied to South Africa's four regions); ZMB: Zambia. Growth rates of Meat supply refer to poultry meat from Traditional Chicken and Commercial Broiler systems. Only the first 11 years of the 16-year data trend used are here presented. 
Appendix Table 6: Exogenous growth rate of Maize yields under baseline and drought conditions to 2025

\begin{tabular}{|c|c|c|c|c|c|c|c|c|c|c|c|}
\hline Region & Location & 2016 & 2017 & 2018 & 2019 & 2020 & 2021 & 2022 & 2023 & 2024 & 2025 \\
\hline \multicolumn{12}{|c|}{ Baseline Scenario } \\
\hline MWI & Urban & 0.028551 & 0.026919 & 0.026959 & 0.027002 & 0.027051 & 0.027521 & 0.026644 & 0.026719 & 0.026788 & 0.026067 \\
\hline $\mathrm{MOZ}$ & Urban & 0.023440 & 0.021778 & 0.021818 & 0.021860 & 0.021909 & 0.022377 & 0.018993 & 0.019066 & 0.019135 & 0.018420 \\
\hline SAF & Urban & 0.017179 & 0.015561 & 0.015607 & 0.015655 & 0.015921 & 0.016205 & 0.010564 & 0.010625 & 0.010681 & 0.010116 \\
\hline ZMB & Urban & 0.009820 & 0.008018 & 0.008057 & 0.008099 & 0.008148 & 0.008609 & 0.006317 & 0.006390 & 0.006458 & 0.005752 \\
\hline MWI & Rural & 0.032571 & 0.030941 & 0.030981 & 0.031024 & 0.031074 & 0.031545 & 0.020511 & 0.020585 & 0.020654 & 0.019938 \\
\hline $\mathrm{MOZ}$ & Rural & 0.023155 & 0.021771 & 0.021862 & 0.021955 & 0.022053 & 0.022570 & 0.012471 & 0.012558 & 0.012640 & 0.011943 \\
\hline SAF & Rural & 0.013821 & 0.013190 & 0.013350 & 0.013513 & 0.013680 & 0.013911 & 0.007889 & 0.007981 & 0.008069 & 0.007536 \\
\hline ZMB & Rural & 0.019638 & 0.017843 & 0.017883 & 0.017925 & 0.017974 & 0.018440 & 0.007394 & 0.007466 & 0.007534 & 0.006827 \\
\hline \multicolumn{12}{|c|}{ Drought Scenario } \\
\hline MWI & Urban & 0.028551 & 0.026988 & 0.027015 & 0.027047 & 0.027088 & 0.027552 & 0.026647 & 0.026721 & 0.026790 & 0.026070 \\
\hline $\mathrm{MOZ}$ & Urban & 0.023440 & 0.021847 & 0.021873 & 0.021905 & 0.021946 & 0.022408 & 0.018995 & 0.019069 & 0.019137 & 0.018423 \\
\hline SAF & Urban & 0.017179 & 0.015617 & 0.015652 & 0.015691 & 0.015950 & 0.016230 & 0.010566 & 0.010627 & 0.010683 & 0.010119 \\
\hline ZMB & Urban & 0.009820 & 0.008086 & 0.008112 & 0.008144 & 0.008184 & 0.008640 & 0.006320 & 0.006393 & 0.006460 & 0.005755 \\
\hline MWI & Rural & 0.032571 & 0.031011 & 0.031037 & 0.031070 & 0.031111 & 0.031577 & 0.020514 & 0.020588 & 0.020656 & 0.019941 \\
\hline MOZ & Rural & 0.023155 & 0.021840 & 0.021918 & 0.022000 & 0.022091 & 0.022601 & 0.012474 & 0.012561 & 0.012643 & 0.011946 \\
\hline SAF & Rural & 0.013821 & 0.013245 & 0.013395 & 0.013550 & 0.013711 & 0.013937 & 0.007892 & 0.007983 & 0.008071 & 0.007540 \\
\hline ZMB & Rural & 0.019638 & 0.017912 & 0.017938 & 0.017970 & 0.018011 & 0.018471 & 0.007396 & 0.007469 & 0.007537 & 0.006830 \\
\hline
\end{tabular}

Source: Authors' adaptation of IMPACT model simulations of moderate economic growth under constant 2005 climate (Base) and moderate growth, climate change (Drought) scenarios (Robinson et al., 2015). MWI: Malawi; MOZ: Mozambique; SAF: South Africa (applied to South Africa's four regions); ZMB: Zambia. Only the first 11 years of the 16-year data trend used are here presented. 